\title{
Heterogeneity, monetary policy, Mirrleesian taxes, and the Friedman rule*
}

\author{
Firouz Gahvari ${ }^{\dagger}$ \\ Luca Micheletto $\ddagger$
}

${ }^{*}$ We would like to thank three anonymous referees for their many constructive and helpful comments.

${ }^{\dagger}$ Department of Economics, University of Illinois at Urbana-Champaign, USA. E-mail address: fgahvari@illinois.edu

${ }^{\ddagger}$ Department of Law, University of Milan, Italy; Dondena Centre for Research on Social Dynamics and Public Policy, Bocconi University, Milan, Italy ; UCFS Uppsala, Sweden; CESifo Germany. E-mail address: luca.micheletto@unimi.it; phone number: +39 0250312644. 


\begin{abstract}
We consider an overlapping-generations economy with money rationalized through a cash-in-advance constraint and heterogeneous agents subject to nonlinear taxation of labor income and linear taxation of commodity purchases. Some agents are more productive and more financially connected than others leading to their earning more income and requiring a proportionately smaller cash reserve to mediate their expenditures. We show that a nonlinear income tax can always fully neutralize the redistributive implications of who gets the extra money. On the other hand, with differences in financial connectedness, the tax policy cannot neutralize the redistributive implications of the monetary growth rate. Nevertheless the Friedman rule is found to be often desirable as a corner solution without having to impose arbitrary restrictions on the structure of agents' preferences. At the same time, the differences in connectedness may result in the violation of the Friedman rule.
\end{abstract}

JEL classification: D82; E52; H21.

Keywords: Monetary policy, fiscal policy, redistribution, the Friedman rule, second best. 


\section{Introduction}

This paper attempts to shed light on two inter-related questions. One is the redistributive properties of monetary policy; the other concerns the optimality of the Friedman rule (hereafter FR) of setting the nominal interest rate to zero (Friedman 1969). The two questions are related in that the monetary policy affects redistribution through the monetary growth rate as well as money disbursement rule. The setting that we consider is a Mirrleesian optimal tax framework wherein available tax instruments are rationalized by what are considered the most realistic assumptions about the structure of information in the economy. The novelty of our approach is to allow for two sources of heterogeneity among agents. In addition to differences in earning abilities, which is the hallmark of Mirrleesian models, we allow agents to differ in the degree of sophistication in handling of, and access to, financial markets. Additionally, we do not make any arbitrary assumptions about the individuals' structure of preferences.

The question of redistributive properties of monetary policy is important not only in its own right but also to the resolution of the debate regarding the impropriety of giving redistributive power, which should reside with the legislature, to unelected central bankers. In considering the Mirrleesian approach to address the optimality of the FR, we follow da Costa and Werning (2008). Their paper represents a refreshing break from the traditional public finance approach to this question which typically studies the problem in environments with identical individuals. Such environments are, by construct, silent on the validity of FR when monetary policy has redistributive implications. ${ }^{1}$ Naturally too, these earlier studies use a Ramsey tax setting and assume that all tax instruments, including the income tax, are set proportionally. ${ }^{2}$ Yet, while recognizing the significance of heterogeneity in studying the FR, da Costa and Werning (2008) focus on heterogeneity

\footnotetext{
${ }^{1}$ With the exception of intergenerational redistributive issues that arise in overlapping generations models; see, e.g., Weiss (1980), Abel (1987), and Gahvari (1988).

${ }^{2}$ See, e.g., Chari et al. (1991, 1996), Correia and Teles (1996, 1999), Guidotti and Vegh (1993), Mulligan and Sala-i-Martin (1997), and De Fiore and Teles (2003).
} 
in productivities in the labor market but ignore other sources of heterogeneity that are potentially important in this context.

One source is the distinction that Williamson (2008) has made between "connected" and "unconnected" agents in terms of their access to and reliance on financial institutions. He shows that this kind of heterogeneity causes monetary policy to have significant redistributive implications which, in turn, often leads to a negation of the FR. Yet, Williamson does not frame this distinction within an optimal tax framework. As such it is difficult to draw any conclusions for the effects of this type of heterogeneity on the validity of the FR within an optimal tax setting. The current paper is a first attempt at studying and providing an answer to this question.

In da Costa and Werning's (2008) Mirrleesian framework, the FR emerges either as an interior or as a corner solution. To put these results in perspective, one should consider that the FR is a first-best prescription which may or may not hold in secondbest settings. This depends on the nature of the second-best (existence of distortionary taxes or intrinsic reasons for market failure), the set of tax instruments available to the government, and the structure of individuals' preferences. ${ }^{3}$ Chari et al. $(1991,1996)$, in the context of a model with identical and infinitely-lived individuals, related the optimality of FR in the presence of distortionary taxes to the uniform commodity tax result of Atkinson and Stiglitz (1972) and Sandmo (1974). This latter result states that if preferences are separable in labor supply and non-leisure goods, with the subutility

\footnotetext{
${ }^{3}$ Among other authors, Bloise and Polemarchakis (2006), Ireland (2003), and Rochon and Polemarchakis (2006) showed that zero nominal interest rates constitute a necessary condition for Pareto optimality. The optimality of the FR when lump-sum taxes are not available is more controversial. The non-optimality of the FR in the presence of distortive taxes was first discussed by Phelps (1973). Cunha (2008) investigates whether zero nominal interest rates constitute a feature of optimal policies associated with complete and incomplete tax systems (where a tax system is defined incomplete if the number of tax instruments is smaller than the number of wedges). A selective reference to other sources of distortion include: van der Ploeg and Alogoskoufis (1994) for an externality underlying endogenous growth; Ireland (1996) for monopolistic competition; Erceg et al. (2000) and Khan et al. (2003) for nominal wage and price settings; Schmitt-Grohe and Uribe (2004a,b) for imperfections in the goods market; Lai and Chin (2010) for imperfections in the (world) capital markets; and Shaw et al. (2006) for imperfect competition as well as externality.
} 
for goods being homothetic, optimal commodity taxes are proportionately uniform. Deviations from the FR violates this tax principle. ${ }^{4}$

As with Chari et al.'s (1991, 1996) earlier result, da Costa and Werning's (2008) finding is also related to the uniform taxation result in public finance, albeit a different one. Whereas Chari et al.'s $(1991,1996)$ draws on Sandmo's tax uniformity (1974) result derived within a Ramsey setting, da Costa and Werning's (2008) has its roots in Atkinson and Stiglitz (1976). That classic paper on the design of tax structures was particularly concerned with the usefulness of commodity taxes in the presence of a general income taxes in many-consumer economies. ${ }^{5}$ It proved that with a general income tax, if preferences are weakly separable in labor supply and non-leisure goods, commodity taxes are not needed as instruments of optimal tax policy. The preference separability implies a zero nominal interest rate and underlies da Costa and Werning's (2008) result as an interior solution.

With non-separability, one wants to tax the goods that are "substitutes" with labor supply and subsidize those that are "complements" with labor supply. ${ }^{6}$ da Costa and Werning assume that real cash balances and labor supply are complements so that cash balances should be subsidized. This implies that the optimal nominal interest rate is

\footnotetext{
${ }^{4}$ This uniformity result is derived within the context of the traditional one-consumer Ramsey problem. As such, the result embodies only efficiency considerations. Redistributive goals play no role.

${ }^{5}$ The ineffectiveness of commodity taxes and their proportionately uniform tax treatment boil down to the same thing. In the absence of exogenous incomes, the government has an extra degree of freedom in setting its income and commodity tax instruments. This is because all demand and supply functions are homogeneous of degree zero in consumer prices and lump-sum income. In consequence, the government can, without any loss of generality, set one of the commodity taxes at zero (i.e. set one of the commodity prices at one). Under this normalization, uniform rates imply absence of commodity taxes.

${ }^{6}$ The result is based on the "normal" assumption that the socially desirable direction of redistribution goes from high-skilled to low-skilled agents. The substitutability/complementarity relationships allow commodity taxes/subsidies to weaken otherwise binding self-selection constraints. As Stiglitz (2015, p. 42) writes: "what the Atkinson-Stiglitz theorem illustrates is that in the presence of an (optimal) income tax , ... commodity taxation can be viewed as a particular type of Pigouvian corrective tax. The focus is not on the impact on tax revenues, or even directly on dead weight losses (as usually conceived), but on impacts on the self-selection constraints that are central to the design of the optimal income tax. 'Loosening' the self-selection constraints has a first order effect on welfare, while the distortions associated with small commodity taxation have a second order effect on welfare."
} 
negative. But given the non-negativity of nominal interest rate, the FR emerges as the "optimal" policy. The question then is what justifies da Costa and Werning's complementarity assumption. The justification appears to come from "the notion, stressed by various theories, that money's liquidity services facilitate transactions and save on the time required for purchases" (da Costa and Werning, 2008, p. 83). However, the chosen complementarity assumption does not lead to or explain the empirical regularity found in the literature to the effect that the lower income consumers carry a higher percentage of their expenditures in cash. ${ }^{7}$ Indeed, as Albanesi (2007) points out, the complementarity assumption exploited by da Costa and Werning "would lead to a crosssectional distribution of money holdings that is inconsistent with empirical evidence" (p. 38). And, without recourse to this assumption, the optimality of the FR remains questionable.

We account for the negative cross-sectional correlation between money holdings and labor income by explicitly modeling it as the outcome of the "connectedness" heterogeneity that Williamson (2008) proposed while remaining agnostic about the structure of individuals' preferences (i.e. complementarity or substitutability of real balances with labor supply). As Williamson pointed out, individuals relying more on financial instruments, require to carry less cash to finance their transactions. One can think of two mechanisms for the ability to fully exploit financial institutions. One is a person's actual income level. There is abundant empirical evidence that wealthier people, in developed and developing countries alike, have wider access to financial institutions; see, e.g., Johnson and Sherraden (2007). A second mechanism that likely plays a role is an individual's "financial acumen" (by which we mean both one's innate ability in this

\footnotetext{
${ }^{7}$ See, e.g., Mulligan and Sala-i-Martin (2000), Erosa and Ventura (2002), and Guiso et al. (2001). The complementarity assumption only tells us that if a high-ability consumer and a low-ability consumer were to earn the same gross-of-tax income and the same net-of-tax income, the high-ability consumer (whose labor supply is lower since his wage rate is higher) would carry a smaller amount of real cash balances than the low-ability consumer. It does not tell us if, in equilibrium, a high-ability person (earning a higher income than a low-ability individual) will in fact carry a smaller amount of real cash balances, as a percentage of his total expenditures, than a low-ability consumer.
} 
particular dimension as well as one's financial literacy). ${ }^{8}$ Indeed, Johnson and Sherraden (2007) recognize and document both of the two mechanisms mentioned under "access to financial institutions and services" and "financial knowledge" (with the two elements forming what they call "financial capability"). ${ }^{9}$ Similarly, in its Policy Brief (July 2006), the OECD reports that "The information available on consumer financial literacy is worrying"; it further adds that "The level of financial literacy tends to vary according to education and income levels, but the evidence shows that highly educated consumers with high incomes can be just as ignorant about financial issues as less educated, lower income consumers". ${ }^{10}$ Naturally, one expects one's financial acumen to be positively correlated with one's earning ability and productivity. ${ }^{11}$

Modeling differences in financial connectedness directly, obviates the need to import forced assumptions that will have their own artifacts. Indeed, if "money's liquidity services facilitate transactions and save on the time required for purchases", as da Costa and Werning (2008) argue, one would expect the rich and more able individuals to want to carry relatively more cash, not less. Their time is after all more valuable and productive than the poor and less-able individuals'.

To model financial connectedness as a second source of heterogeneity, we rationalize money holdings through a Clower cash-in-advance constraint that allows for the cash reserve requirement to differ across agents. Individuals who are more financially sophisticated are postulated to require a smaller fraction of their expenditures to be financed through cash reserves. This fraction is also assumed to vary inversely with one's earned

\footnotetext{
${ }^{8}$ Mirrleesian models, being static in nature, do not explicitly model the role that education plays in the outcome. In postulating that earnings are simply the product of earning ability and effort (labor supply), one subsumes the role of education in one's "innate abilities" (boosting it up).

${ }^{9}$ That financial sophistication is not identical to access is supported by other type of evidence as well. For example, Kotlikoff and Bernheim (2001) report that having an allowance and a bank account in childhood leads to more savings in adulthood.

${ }^{10}$ The Policy Brief also mentions that OECD is advancing a project entitled "Improving Financial Literacy" and has suggested ten specific guidelines for improving financial literacy.

${ }^{11}$ Of course, given that in equilibrium higher earning abilities are translated into higher earnings, the two mechanisms are interrelated. Yet, as we will see later in Section 6, the two are not the same and each has its own distinct implication.
} 
income. $^{12}$

Another difference between our setup and the one considered by da Costa and Werning (2008) is that we use an overlapping-generations (hereafter OLG) framework instead of an infinitely-lived cohort of agents. This allows us avoiding certain technical difficulties while concentrating on our main points. However, as the "golden rule" literature has taught us, in the OLG models one can always exploit the difference between the real interest rate and the population growth rate to raise the steady-state welfare through intergenerational wealth transfers. ${ }^{13}$ Distortionary commodity taxes achieve this. An inflation tax, i.e. deviating from the FR, is one such mechanism. ${ }^{14}$ However, this reason for the suboptimality of the FR has nothing to do with the heterogeneity of agents or with the existence of Mirrleesian taxes (the issues of interest in this paper). Thus, to avoid distraction caused by this obvious source of suboptimality, when discussing the optimality of the FR in our setup, we shall assume that the economy is at the golden rule.

A number of lessons emerge from our analysis. First, regarding the role of income and commodity taxes, we distinguish between two monetary mechanisms that can affect redistribution. One concerns who gets the extra money. The other is associated with the rate of growth of money supply. We show that a nonlinear income tax can always neutralize the first mechanism. On the other hand, the tax policy can neutralize the second redistributive channel only in the absence of differences in financial connectedness.

Second, absent differences in financial connectedness, we show there is instrument

\footnotetext{
${ }^{12}$ We find the cash-in-advance constraint formulation to be the simplest mechanism for introducing a second source of heterogeneity into the model. This is in contrast to da Costa and Werning (2008) who rationalize money holdings via introducing real cash balances in the agents' utility functions. These "reduced-form" formulations are the literature's two most commonly used environments for studying the optimality of the FR.

${ }^{13}$ The terminology and the original formulation of the golden rule, in the context of the neoclassical growth model, is due to Phelps (1961). For discussions in the context of OLG model, see, among others, Diamond (1965) and Hamada (1972).

${ }^{14}$ This result was first demonstrated by Weiss (1980). Later, Gahvari (1988) showed that the existence of generation-specific lump-sum taxes makes the use of such distortionary taxes unnecessary and restores the optimality of the FR.
} 
"over-determination". That is, the optimal monetary growth rate is not unique; a continuum of values satisfies it (supported by offsetting tax instruments). To have a unique optimal monetary growth rate, commodity taxation must be ruled out. Under this circumstance, the FR holds as a unique interior solution if preferences are separable in labor supply. It will also hold as a corner solution if labor supply and second-period consumption are complements.

Third, with differences in financial connectedness, the over-determinacy disappears and the optimal policy is characterized by a unique commodity tax rate and a unique monetary growth rate. Provided that labor supply and second-period consumption are substitutes, it might then be optimal to violate the FR. However, for this to happen one also needs that the differences in financial connectedness are to a sufficiently large extent explained by differences in income (rather than by an underlying heterogeneity in financial sophistication).

\section{The model}

Consider a two-period OLG model wherein individuals work in the first period and consume in both. There is no bequest motive. Preferences are represented by the strictly quasi-concave utility function $U=u\left(c_{t}, d_{t+1}, L_{t}\right)$ where $c$ denotes consumption in the first period, $d$ consumption in the second period, and $L$ denotes the labor supply; subscript $t$ denotes calendar time. The utility function is strictly increasing in $c_{t}$ and $d_{t+1}$, and strictly decreasing in $L_{t}$. Each generation consists of two types of individuals who differ in two (positively) correlated characteristics: earning abilities (labor productivity) and the degree of "financial sophistication". High-productivity workers are paid $w_{t}^{h}$

and low-productivity workers $w_{t}^{\ell}$; with $w_{t}^{h}>w_{t}^{\ell}$. The degree of financial sophistication, together with the income earned by a given individual, determines an agent's degree of "financial connectedness". This is modeled by the relative size of the cash one has to carry for financing his transactions. The proportion of agents of type $j, \pi^{j}, j=h, \ell$, 
remains constant over time. Denote the number of young agents of type $j$ born in period $t$ by $n_{t}^{j}$ and the total number of young agents by $N_{t}$. We have $n_{t}^{j} / N_{t}=\pi^{j}$. While $\pi^{j}$ remains constant, population grows over time at a constant rate, $g$.

Production takes place through a linear technology with different types of labor as inputs. Transfer of resources to the future occurs only through a storage technology with a fixed (real) rate of return, $r .{ }^{15}$ We thus work with an OLG model à la Samuelson (1958) and assume away the issues related to capital accumulation.

\subsection{Money and monetary policy}

Money holdings, rationalized through a Clower cash-in-advance constraint, constitute another source of financing for future consumption (in addition to real savings). At the beginning of period $t$, before consumption takes place, the young purchase all the existing stock of money, $M_{t}$, from the old. Denote a young $j$-type agent's purchases by $m_{t}^{j}$. We have

$$
M_{t}=n_{t}^{h} m_{t}^{h}+n_{t}^{\ell} m_{t}^{\ell}
$$

The rate of return on money holdings (the nominal interest rate), $i_{t+1}$, is related to the inflation rate, $\varphi_{t+1}$, according to the Fisher equation

$$
1+i_{t+1} \equiv(1+r)\left(1+\varphi_{t+1}\right)
$$

Denote the price level at time $t$ by $p_{t}$; the inflation rate is defined as

$$
1+\varphi_{t+1} \equiv p_{t+1} / p_{t}
$$

The monetary authority injects money into (or retires money from) the economy at the constant rate of $\theta .{ }^{16}$ The formulation below is based on the "assumption" that the

\footnotetext{
${ }^{15}$ An alternative assumption is that agents borrow and lend on international capital markets at an exogenously fixed interest rate.

${ }^{16}$ Given a positive real interest rate, in the absence of population growth, $\theta$ will have to be negative for the nominal interest rate to be zero as required by the FR. With population growth, the FR is compatible with a positive $\theta$ (as well as a negative $\theta$ ). Either way, the fact that the nominal interest rate cannot be negative sets a lower bound on $\theta$.
} 
money is given to (or taken from) the old - who hold all the stock of money. Let $a_{t+1}^{j}$ denote the amount of money that a $j$-type agent, who purchases $m_{t}^{j}$ at the beginning of time $t$, "receives" at the beginning of period $t+1$. Clearly, $a_{t+1}^{h}$ and $a_{t+1}^{\ell}$ must satisfy the "money injection relationship",

$$
n_{t}^{h} a_{t+1}^{h}+n_{t}^{\ell} a_{t+1}^{\ell}=\theta M_{t}
$$

Beyond this, we do not specify how much of the extra money injection goes to which type. Indeed, one message of our paper is to prove that this division is immaterial.

Following Hahn and Solow (1995), specify the cash-in-advance constraint through the assumption that all agents must finance a certain fraction of their second-period consumption expenditures by the cash balances saved in the first period. ${ }^{17}$ However, given our heterogeneous-agents framework, this fraction is allowed to depend on an individual's type as well as on his earned income. Specifically, let $I$ denote earned income and let $\gamma^{j}(I)$ denote the fraction of a $j$-type's second-period consumption expenditures that has to be financed by cash balances when earning $I$. One can write his cash-inadvance constraint by, ${ }^{18}$

$$
m_{t}^{j}+a_{t+1}^{j} \geqq \gamma^{j}(I) p_{t+1} d_{t+1}^{j}
$$

An interesting feature of the cash-in-advance constraint approach to modeling money holdings is that it can be tweaked in a natural way to account for the kind of heterogeneity Williamson (2008) has identified. His notion of connectedness can be captured

\footnotetext{
${ }^{17}$ This specification has been used extensively in overlapping-generations models, particularly by Philippe Michel and his associates; see, e.g., Crettez et al. (1999, 2002) and Michel and Wigniolle (2003, 2005). This specification may appear restrictive in that it does not apply to first-period consumption expenditures. However, this is not the case for the points addressed in this paper. Assuming that first-period expenditures are also subject to this constraint does not change our results. Given that individuals have no assets in the first-period, they will have to borrow money from the old, at the market interest rate, and as such imposes no additional constraint on the individuals' optimization problem. See Gahvari (2012) for more details on what might change if one adopts this more generalized specification for the cash-in-advance constraint.

${ }^{18}$ With the additional restriction that $-m_{t}^{j}<a_{t+1}^{j}<\gamma^{j} p_{t+1} d_{t+1}^{j}$. Observe also that $m_{t}^{j}+a_{t+1}^{j}$ is not necessarily equal to $(1+g) m_{t+1}^{j}$. This will be the case only if the money disbursement to type $j$ is set according to the rule $a_{t+1}^{j}=\theta m_{t}^{j}$.
} 
through differences in individual characteristics and incomes. On one hand higher productivity goes hand in hand with a higher inherent degree of sophistication on the part of the individual, and the more sophisticated an individual, the higher his knowledge of the financial sector and his ability to take advantage of financial institutions. At the same time, the more income an individual earns, the more "connections" he makes (higher incomes open more doors). Both of these factors appear to be behind Williamson's concept of financial connectedness allowing richer individuals to carry a smaller fraction of their expenditures in cash. Put differently, $\gamma^{\ell}(I)>\gamma^{h}(I)$, with $\partial \gamma^{j}(I) / \partial I<0$ (for $j=\ell, h)$. Moreover, since at the solution to the government's problem that we present in Section 2.4 the high-productivity individuals earn more than the low-productivity ones, i.e. $I^{h}>I^{\ell}$, we will have that $\gamma^{\ell}\left(I^{\ell}\right)>\gamma^{h}\left(I^{h}\right) \cdot{ }^{19}$

\subsection{Fiscal policy}

Informational frictions play a key role in the Mirrleesian optimal tax approach. The informational structure we posit is the one most commonly used in the optimal tax literature; see, e.g., Edwards et al., (1994). In particular, we shall assume that an individual's type and labor supply are not publicly observable; hence first-best type-specific lump-sum taxes are not available and redistribution can be achieved only through distortionary taxation. On the other hand, individual income $\left(I_{t}=w_{t} L_{t}\right)$ is observable so that it can be taxed via a nonlinear tax schedule $T\left(I_{t}\right)$. Moreover, we assume that the tax administration has information on anonymous transactions but not on the identity of the consumers. That is, the administration observes the total sales of a commodity

\footnotetext{
${ }^{19}$ Interestingly too, our setup lends itself to a natural reinterpretation in terms of cash and credit goods. With two consumption goods in our model, first-period and second-period, and individuals having to hold cash only for financing a fraction of the second-period consumption, one can think of the first-period consumption good as credit goods and the second-period consumption good as part cash part credit goods. Seen in this light, one naturally wonders about the optimality of the FR if the government were to levy different tax rates on first- and second-period consumption goods. As we show later in the paper, the answer to this question depends crucially on what kind of tax instrument is available to the government. Linear consumption taxes do not suffice to make the inflation tax redundant. What one would need for this purpose is a non-linear commodity tax.
} 
but not who bought how much. This is the standard assumption in the literature so much so that it has been used as part of the very definition of indirect taxation. In discussing direct versus indirect taxation, Atkinson and Stiglitz (1980) write "the essential aspect of the distinction [is] the fact that direct taxes may be adjusted to the individual characteristics of the taxpayer, whereas indirect taxes are levied on transactions irrespective of the circumstances of buyer or seller" (p. 427). This assumption precludes imposition of non-linear commodity taxes. ${ }^{20}$ However, linear commodity taxation is feasible. ${ }^{21}$

When determining the linear commodity taxes, however, the homogeneity of degree zero of demands in consumer prices and disposable incomes, implies that the tax authority has one extra degree of freedom in setting the commodity tax rates. As long as relative prices of the various goods are kept fixed, any effect of a proportionately uniform increase or decrease in the vector of commodity tax rates can be offset via a proper adjustment in the income tax schedule. One of the tax rates can then be set equal to zero without any loss of generality. We set the tax rate on $c_{t}$ equal to zero normalizing its consumer price to one. The tax rate on $d_{t+1}$ is denoted by $\tau$. Giving the linearity of the production technology, we also normalize all producer prices to one (by suitable choices of measurement units).

\subsection{Constrained Pareto-efficient allocations}

To characterize the (constrained) Pareto-efficient allocations, one has to account for the economy's resource balance, the incentive compatibility (hereafter IC) constraints due to our informational structure, and the implementability constraints caused by linearity of commodity taxes (itself due to informational constraint) as well as the monetary expansion mechanism. To this end, we derive an optimal revelation mechanism. For

\footnotetext{
${ }^{20}$ For completeness, we nevertheless investigate the implications of the availability of nonlinear commodity taxes in our model. This is discussed in Appendix $\mathrm{C}$ of the paper.

${ }^{21}$ The required information for this type of taxation, particularly if it is levied on producers, is indeed public observability of anonymous transactions.
} 
our purpose, a mechanism consists of a set of type-specific before-tax labor incomes, $I_{t}^{j}$ s, after-tax incomes, $z_{t}^{j}$ s, a commodity tax rate, $\tau$, a money supply growth rate, $\theta$, and a monetary distributive rule, $a_{t+1}^{j} \cdot{ }^{22}$ This procedure determines $\tau, \theta$, and $a_{t+1}^{j}$ from the outset. A complete solution to the optimal tax problem per se, i.e. determination of $I_{t}^{j}$ by the individuals via utility maximization, then requires only the design of a general income tax function $T\left(I_{t}\right)$ such that $z_{t}^{j}=I_{t}^{j}-T\left(I_{t}^{j}\right)$.

To proceed further, it is necessary to consider the optimization problem of an individual for a given mechanism $\left(\tau, \theta, a_{t+1}, z_{t}, I_{t}\right)$. This is necessitated by the fact that the mechanism determines personal consumption levels only indirectly, namely through prices. The mechanism assigns the quintuple $\left(\tau, \theta, a_{t+1}^{j}, z_{t}^{j}, I_{t}^{j}\right)$ to a young individual who reports his type as $j .{ }^{23}$ The individual will then allocate $z_{t}^{j}$ between first- and second-period consumption, and money holdings.

Formally, given any vector $\left(\tau, \theta, a_{t+1}, z_{t}, I_{t}\right)$, an individual of type $j$ chooses $c_{t}$ and $d_{t+1}$ to maximize

$$
u=u\left(c_{t}, d_{t+1}, \frac{I_{t}}{w_{t}^{j}}\right), \quad j=\ell, h,
$$

subject to the per-period budget constraints

$$
\begin{aligned}
& p_{t}\left(c_{t}+s_{t}\right)+m_{t}=p_{t} z_{t}, \\
& p_{t+1}(1+\tau) d_{t+1}=p_{t} s_{t}\left(1+i_{t+1}\right)+m_{t}+a_{t+1},
\end{aligned}
$$

where $s_{t}$ is the level of real savings chosen by the agent. Observe that $\theta$ does not explicitly appear in the problem above; it does so implicitly through its effect on $i_{t+1}$.

Combining equations (7)-(8) we can write the intertemporal budget constraint for

\footnotetext{
${ }^{22}$ Observe that the monetary authority has only two degrees of freedom in setting $a_{t+1}^{\ell}, a_{t+1}^{h}$ and $\theta$. Setting any two of these three variables fixes the third through equation (4).

${ }^{23}$ If the money disbursements to skilled and unskilled workers were set according to $a_{t+1}^{j}=\theta m_{t}^{j}$, then once $\theta$ is determined, so will $a_{t+1}^{j}$. The revelation mechanism will then be reduced to a quadruple $\left(\tau, \theta, z_{t}^{j}, I_{t}^{j}\right)$.
} 
the young as: ${ }^{24}$

$$
c_{t}+\frac{(1+\tau) d_{t+1}}{1+r}+\frac{i_{t+1}}{1+r} \frac{m_{t}}{p_{t+1}}=z_{t}+\frac{a_{t+1}}{p_{t+1}(1+r)}
$$

The problem of a young $j$-type, who is facing the quintuple $\left(\tau, \theta, a_{t+1}^{j}, z_{t}^{j}, I_{t}^{j}\right)$, is to determine $c_{t}, d_{t+1}$, and $m_{t}$ to maximize (6) subject to (9) and the cash-in-advance constraint (5). Summarizing this problem by the Lagrangian,

$$
\begin{aligned}
\mathcal{L}=u\left(c_{t}, d_{t+1}, \frac{I_{t}}{w_{t}^{j}}\right) & +\lambda\left[z_{t}+\frac{a_{t+1}}{p_{t+1}(1+r)}-c_{t}-\frac{(1+\tau) d_{t+1}}{1+r}-\frac{i_{t+1}}{1+r} \frac{m_{t}}{p_{t+1}}\right] \\
& +\mu\left[\frac{m_{t}}{p_{t+1}}+\frac{a_{t+1}}{p_{t+1}}-\gamma^{j} d_{t+1}\right],
\end{aligned}
$$

the first-order conditions are:

$$
\begin{aligned}
\frac{\partial \mathcal{L}}{\partial c_{t}} & =\frac{\partial u\left(c_{t}, d_{t+1}, I_{t} / w_{t}^{j}\right)}{\partial c_{t}}-\lambda=0, \\
\frac{\partial \mathcal{L}}{\partial d_{t+1}} & =\frac{\partial u\left(c_{t}, d_{t+1}, I_{t} / w_{t}^{j}\right)}{\partial d_{t+1}}-\lambda \frac{1+\tau}{1+r}-\mu \gamma^{j}=0, \\
\frac{\partial \mathcal{L}}{\partial\left(m_{t} / p_{t+1}\right)} & =-\lambda \frac{i_{t+1}}{1+r}+\mu=0 .
\end{aligned}
$$

Assuming the cash-in-advance constraint (5) is binding, the above conditions yield: ${ }^{25}$

$$
\frac{\partial u\left(c_{t}, d_{t+1}, I_{t} / w_{t}^{j}\right) / \partial d_{t+1}}{\partial u\left(c_{t}, d_{t+1}, I_{t} / w_{t}^{j}\right) / \partial c_{t}}=\frac{1+\tau+\gamma^{j}\left(I_{t}\right) i_{t+1}}{1+r} \equiv q_{t+1}^{j}\left(I_{t}\right) .
$$

\footnotetext{
${ }^{24}$ Substitute $z_{t}-c_{t}-m_{t} / p_{t}$ for $s_{t}$ from (7) into (8) to derive,

$$
\begin{aligned}
p_{t+1}(1+\tau) d_{t+1} & =p_{t}\left(z_{t}-c_{t}-\frac{m_{t}}{p_{t}}\right)\left(1+i_{t+1}\right)+m_{t}+a_{t+1} \\
& =p_{t+1}\left[z_{t}-c_{t}-\frac{m_{t}}{p_{t+1}}\left(1+\varphi_{t+1}\right)\right](1+r)+m_{t}+a_{t+1} .
\end{aligned}
$$

Divide the above expression by $p_{t+1}(1+r)$ and rearrange.

${ }^{25}$ If the constraint (5) is non-binding then $\mu=0$ and, from (12), $i_{t+1}=0$ (because $\lambda>0$ ). Under this circumstance, $i_{t+1}=0$ emerges simply as a condition for households to hold money and the question of the optimality of the FR becomes a moot point.
} 
Writing the binding version of the Clower cash-in-advance constraint as, ${ }^{26}$

$$
\frac{m_{t}^{j}}{p_{t+1}}=\gamma^{j}\left(I_{t}\right) d_{t+1}^{j}-\frac{a_{t+1}^{j}}{p_{t+1}}
$$

we can incorporate (14) into the intertemporal budget constraint (9) to rewrite it as ${ }^{27}$

$$
c_{t}+\frac{1+\tau+\gamma^{j}\left(I_{t}\right) i_{t+1}}{1+r} d_{t+1}=z_{t}+\frac{a_{t+1}}{p_{t}} .
$$

Condition (13) and the young $j$-type's intertemporal budget constraint (15), using the definition of $q_{t+1}^{j}$ in (13), yield the following conditional demands for the $j$-type's firstand second-period consumption, ${ }^{28}$

$$
c_{t}^{j}=c\left(q_{t+1}^{j}\left(I_{t}\right), z_{t}+\frac{a_{t+1}}{p_{t}}, \frac{I_{t}}{w_{t}^{j}}\right), \quad d_{t+1}^{j}=d\left(q_{t+1}^{j}\left(I_{t}\right), z_{t}+\frac{a_{t+1}}{p_{t}}, \frac{I_{t}}{w_{t}^{j}}\right) .
$$

The $j$-type's holding of cash, $m_{t}^{j}$, is then determined through equation (14). These are of course conditional on the values of $\tau, \theta, a_{t+1}^{j}, z_{t}^{j}, I_{t}^{j}, j=h, \ell$, the policy parameters to be set by the "mechanism designer". ${ }^{29}$

To complete the characterization of the set of (constrained) Pareto-efficient allocations, what is left for us to specify is how the mechanism designer chooses $\left(\tau, \theta, a_{t+1}^{j}, z_{t}^{j}, I_{t}^{j}\right)$. Substituting the values of $c_{t}^{j}$ and $d_{t+1}^{j}$ in the young $j$-type's utility function (6), yields his conditional indirect utility function,

$$
\begin{aligned}
& v\left(q_{t+1}^{j}\left(I_{t}\right), z_{t}+\frac{a_{t+1}}{p_{t}}, \frac{I_{t}}{w_{t}^{j}}\right) \equiv \\
& u\left(c\left(q_{t+1}^{j}\left(I_{t}\right), z_{t}+\frac{a_{t+1}}{p_{t}}, \frac{I_{t}}{w_{t}^{j}}\right), d\left(q_{t+1}^{j}\left(I_{t}\right), z_{t}+\frac{a_{t+1}}{p_{t}}, \frac{I_{t}}{w_{t}^{j}}\right), \frac{I_{t}}{w_{t}^{j}}\right) .
\end{aligned}
$$

\footnotetext{
${ }^{26}$ Divide (5) by $p_{t+1}$, rearrange the terms, and use equations (2)-(3).

${ }^{27}$ Substitute for $m_{t} / p_{t+1}$, from (14) in the intertemporal budget constraint (9) to get

$$
c_{t}+\frac{(1+\tau) d_{t+1}}{1+r}+\frac{i_{t+1}}{1+r}\left(\gamma^{j} d_{t+1}-\frac{a_{t+1}}{p_{t+1}}\right)=z_{t}+\frac{a_{t+1}}{p_{t+1}(1+r)},
$$

then rearrange the terms.

${ }^{28}$ Observe that if there is heterogeneity in cash-in-advance constraint across the types, $\gamma^{h} \neq \gamma^{\ell}$ and the two types will face different effective prices for $d_{t+1}$ relative to $c_{t}: q_{t+1}^{h} \neq q_{t+1}^{\ell}$.

${ }^{29}$ To be specific, equations (1)-(3), equations (13)-(15) for $j=\ell, h$, and the definition of $q_{t+1}^{j}$ in (13) for $j=\ell, h$, give us eleven equations for determining $c_{t}^{j}, m_{t}^{j}, d_{t+1}^{j}, q_{t+1}^{j}, i_{t+1}, \varphi_{t+1}, p_{t+1}$, and $p_{t}$ under the perfect-foresight assumption.
} 
To write the IC constraints, we should also know what fraction of his second-period consumption expenditures a $j$-type who may want to report his type as $k$, the so-called "mimicker" (or $j k$ agent), must finance through cash balances that he saves in the first period. This fraction, $\gamma^{j}\left(I^{k}\right)$, depends on the individual's true type $j$ as well as the income he earns when mimicking the other type (i.e. the income $I^{k}$ intended by the planner for agents of type $k$ only). Consistent with the definition of $q_{t+1}^{j}\left(I_{t}\right)$ in (13), a $j$-type mimicking a $k$-type will face a price of

$$
q_{t+1}^{j}\left(I^{k}\right) \equiv \frac{1+\tau+\gamma^{j}\left(I^{k}\right) i_{t+1}}{1+r}
$$

for his second-period consumption good. For simplicity, from now on we denote:

$$
\gamma^{j} \equiv \gamma^{j}\left(I^{j}\right), \quad \gamma^{j k} \equiv \gamma^{j}\left(I^{k}\right), \quad q_{t+1}^{j} \equiv q^{j}\left(I_{t}^{j}\right), \quad q_{t+1}^{j k} \equiv q^{j}\left(I_{t}^{k}\right) .
$$

Let $\delta^{j}$ 's be positive constants with the normalization $\sum_{j=\ell, h} \delta^{j}=1$. The mechanism designer maximizes

$$
\sum_{j=\ell, h} \delta^{j} v\left(q_{t+1}^{j}, z_{t}^{j}+\frac{a_{t+1}^{j}}{p_{t}}, \frac{I_{t}^{j}}{w_{t}^{j}}\right)
$$

with respect to $\tau, \theta, a_{t+1}^{h}, z_{t}^{\ell}, z_{t}^{h}, I_{t}^{\ell}$ and $I_{t}^{h},{ }^{30}$ subject to the government's budget constraint,

$$
\sum_{j=\ell, h} \pi_{t}^{j}\left(I_{t}^{j}-z_{t}^{j}\right)+\frac{\tau}{1+r} \sum_{j=\ell, h} \pi_{t+1}^{j} d_{t+1}^{j} \geq \bar{R},
$$

the money injection relationship (4), and the IC constraints

$$
\begin{aligned}
& v\left(q_{t+1}^{h}, z_{t}^{h}+\frac{a_{t+1}^{h}}{p_{t}}, \frac{I_{t}^{h}}{w_{t}^{h}}\right) \geq v\left(q_{t+1}^{h \ell}, z_{t}^{\ell}+\frac{a_{t+1}^{\ell}}{p_{t}}, \frac{I_{t}^{\ell}}{w_{t}^{h}}\right), \\
& v\left(q_{t+1}^{\ell}, z_{t}^{\ell}+\frac{a_{t+1}^{\ell}}{p_{t}}, \frac{I_{t}^{\ell}}{w_{t}^{\ell}}\right) \geq v\left(q_{t+1}^{\ell h}, z_{t}^{h}+\frac{a_{t+1}^{h}}{p_{t}}, \frac{I_{t}^{h}}{w_{t}^{\ell}}\right),
\end{aligned}
$$

\footnotetext{
${ }^{30}$ As observed earlier, one needs to determine only two of the variables $a_{t+1}^{\ell}, a_{t+1}^{h}$ and $\theta$. The third will be determined through equation (4).
} 
where $\bar{R}$ is an exogenous per-capita revenue requirement. ${ }^{31}$ We will discuss the solution to this problem, and the properties of the solution, after it reaches its steady-state equilibrium as discussed next.

\subsection{Steady state}

The consumers' optimization problem under perfect foresight assumption, given the mechanism $\left(\tau, \theta, a_{t+1}^{j}, z_{t}^{j}, I_{t}^{j}\right)$, determines $d_{t+1}^{j}$ as a function of $p_{t}$ and $q_{t+1}^{j}$. Equivalently, given the definition of $q_{t+1}^{j}$ in (13) and using equations (2)-(3), $d_{t+1}^{j}$ is determined as a function of $p_{t}$ and $p_{t+1}$. Consequently, through the binding version of (5), $m_{t}^{j}$ too is determined as a function of $p_{t}$ and $p_{t+1} \cdot{ }^{32}$

Now, in the per-period equilibrium of our model laid out in Section 2, the equality of aggregate money demand and aggregate money supply at time $t$ requires, from equation (1), that $N_{t}\left(\pi^{h} m_{t}^{h}+\pi^{\ell} m_{t}^{\ell}\right)=M_{t}$. Divide this relationship by $N_{t} p_{t}$ and rewrite it as,

$$
\pi^{h} \frac{m_{t}^{h}}{p_{t}}+\pi^{\ell} \frac{m_{t}^{\ell}}{p_{t}}=\frac{(1+\theta) M_{t-1}}{N_{t} p_{t}} .
$$

With $m_{t}^{h}$ and $m_{t}^{\ell}$ being function of $p_{t}$ and $p_{t+1}$, given that $\theta, M_{t-1}$, and $N_{t}$ are all predetermined variables, equation (23) defines a relationship between $p_{t}$ and $p_{t+1}$. The dynamics of the model is then described by this equation. The economy reaches a steady-state equilibrium when $p_{t+1}=[(1+\theta) /(1+g)] p_{t} .{ }^{33}$ This implies, using the

\footnotetext{
${ }^{31}$ Observe that (20) represents a generational budget constraint as opposed to a per-period budget constraint.

${ }^{32}$ Dividing the binding version of (5) by $p_{t}$ results in $m_{t}^{j} / p_{t}=\left(\gamma^{j} d_{t+1}^{j} p_{t+1}-a_{t+1}^{j}\right) / p_{t}$.

${ }^{33}$ Notice that with the money stock changing at the rate $\theta$ in every period, $M_{t+1}=(1+\theta) M_{t}$, or equivalently, using eq. (1) and taking into account that the population of each type grows at a constant rate $g$,

$$
\sum_{j=\ell, h} n_{t}^{j}\left(m_{t+1}^{j}-\frac{1+\theta}{1+g} m_{t}^{j}\right)=0
$$

Given that the price level $p_{t}$ evolves over time in the same way for both types, for both $m_{t}^{\ell} / p_{t}$ and $m_{t}^{h} / p_{t}$ to remain constant over time (i.e. to reach a steady-state level), it must be that the ratios $m_{t+1}^{\ell} / m_{t}^{\ell}$ and $m_{t+1}^{h} / m_{t}^{h}$ take the same value: $m_{t+1}^{\ell} / m_{t}^{\ell}=m_{t+1}^{h} / m_{t}^{h}=p_{t+1} / p_{t}$. This in turn implies that at a steady-state the money holding of each type changes in the same direction, and therefore
}

$$
m_{t+1}^{j}=(1+\theta) m_{t}^{j} /(1+g) .
$$


definition of the inflation rate provided by (3), that the steady-state version of eq. (2) is given by:

$$
1+i=(1+r)(1+\theta) /(1+g) .
$$

In steady state, the mechanism designer assigns $I_{t+1}^{j}=I_{t}^{j}, \equiv I^{j}, z_{t+1}^{j}=z_{t}^{j} \equiv z^{j}$, and $a_{t+2}^{j} / p_{t+1}=a_{t+1}^{j} / p_{t} \equiv b^{j}, j=h, \ell$, to whoever states his type to be $j$. The intertemporal price of the second-period consumption a $j$-type faces, $q_{t+1}^{j}$ defined by (13), then takes the following form

$$
q^{j} \equiv \frac{1+\tau+\gamma^{j} i}{1+r} .
$$

Equation (16) determines the steady-state values of the consumption goods $c_{t}^{j}=c_{t+1}^{j}=$ $c^{j}$ and $d_{t}^{j}=d_{t+1}^{j}=d^{j}$. The steady-state level of real cash balances, $x_{t}^{j} \equiv m_{t}^{j} / p_{t}$, will then be determined from (14) and remains constant over time at ${ }^{34}$

$$
x^{j}=\frac{1+\theta}{1+g} \gamma^{j} d^{j}-b^{j} .
$$

It follows from this expression that one can write the steady-state version of the money

Rewriting the equation above as

$$
\frac{m_{t+1}^{j}}{p_{t+1}} \frac{p_{t+1}}{p_{t}}=\frac{1+\theta}{1+g} \frac{m_{t}^{j}}{p_{t}}
$$

it follows that at a steady-state equilibrium $p_{t+1} / p_{t}=(1+\theta) /(1+g)$.

${ }^{34}$ We have $x_{t}^{j} \equiv m_{t}^{j} / p_{t}=\left(m_{t}^{j} / p_{t+1}\right)\left(p_{t+1} / p_{t}\right)$. Substituting for $m_{t}^{j} / p_{t+1}$ from (14) yields

$$
x_{t}^{j}=\left[\gamma^{j}\left(I_{t}\right) d_{t+1}^{j}-\frac{a_{t+1}^{j}}{p_{t+1}}\right] \frac{p_{t+1}}{p_{t}}=\left[\gamma^{j}\left(I_{t}\right) d_{t+1}^{j} \frac{p_{t+1}}{p_{t}}-\frac{a_{t+1}^{j}}{p_{t}}\right]=\left[\gamma^{j} d^{j} \frac{1+\theta}{1+g}-b^{j}\right] .
$$


injection relationship (4) $\mathrm{as}^{35}$

$$
\sum_{j=\ell, h} \pi^{j} b^{j}=\frac{\theta}{1+g} \sum_{j=\ell, h} \gamma^{j} \pi^{j} d^{j}
$$

For future reference, we also note that the steady-state version of the young $j$-type's intertemporal budget constraint, eq. (15), is given by

$$
c^{j}+q^{j} d^{j}=z^{j}+b^{j} \equiv y^{j}
$$

where $y^{j}$ denotes the $j$-type's aggregate disposable income. Similarly, for a $j k$ mimicker, we have that the intertemporal budget constraint is given by $c^{j k}+q^{j k} d^{j k}=z^{k}+b^{k} \equiv y^{k}$, where

$$
q^{j k} \equiv \frac{1+\tau+\gamma^{j k} i}{1+r}
$$

We are now ready to investigate the questions of the redistributive aspects of monetary policy in the presence of Mirrleesian taxes and of the optimality of the FR.

\section{Monetary policy and redistribution}

This section examines the redistributive aspects of (i) how the money is injected into the economy and (ii) the rate of money creation. The following Proposition summarizes our results for each case.

\footnotetext{
${ }^{35}$ To see this, substitute for $M_{t}$ from equation (1) into (4) and divide it by $N_{t} p_{t}$ to get,

$$
\pi^{h} \frac{a_{t+1}^{h}}{p_{t}}+\pi^{\ell} \frac{a_{t+1}^{\ell}}{p_{t}}=\theta\left(\pi^{h} \frac{m_{t}^{h}}{p_{t}}+\pi^{\ell} \frac{m_{t}^{\ell}}{p_{t}}\right) .
$$
}

In the steady state, $a_{t+1}^{j} / p_{t}$ tends to $b^{j}$ and $m_{t}^{j} / p_{t}$ to $x^{j}$, where $x^{j}=[(1+\theta) /(1+g)] \gamma^{j} d^{j}-b^{j}$. Substituting in above,

$$
\pi^{h} b^{h}+\pi^{\ell} b^{\ell}=\theta\left(\pi^{h} x^{h}+\pi^{\ell} x^{\ell}\right)=\theta \frac{1+\theta}{1+g}\left(\pi^{h} \gamma^{h} d^{h}+\pi^{\ell} \gamma^{\ell} d^{\ell}\right)-\theta\left(\pi^{h} b^{h}+\pi^{\ell} b^{\ell}\right),
$$

and rearranging the terms yields,

$$
(1+\theta)\left(\pi^{h} b^{h}+\pi^{\ell} b^{\ell}\right)=\theta \frac{1+\theta}{1+g}\left(\pi^{h} \gamma^{h} d^{h}+\pi^{\ell} \gamma^{\ell} d^{\ell}\right) .
$$

Then divide this expression by $(1+\theta)$. 
Proposition 1 Consider the steady-state equilibrium of our OLG model with cash-inadvance constraint and with heterogeneous agents:

(i) For a given monetary rate of growth, the fiscal authority can always offset the redistributive effects of who gets the extra money (or loses the money that is withdrawn from the economy), by adjusting the nonlinear income tax.

(ii) A change in monetary growth rate changes the relative price of future to present consumption differently for different individuals. The fiscal authority cannot neutralize the effects of such a change in monetary policy.

Proof. To prove part (i), start from any initial value for $b^{h}$ and $b^{\ell}$ and consider a change in money disbursements equal to $d b^{h}$ and $d b^{\ell}$. Simultaneously, change $z^{j}$ according to $d z^{j}=-d b^{j}$. Now, with $y^{j}=z^{j}+b^{j}, d y^{j}=0$, and $\left(q^{j}, y^{j}, I^{j}\right),\left(q^{j k}, y^{k}, I^{k}\right)$ remain intact. Hence the utility of all agents in the economy, including those planning to behave as mimickers, remain the same. As a result, the IC constraints continue to be satisfied if they were satisfied at the initial equilibrium.

Second, with $\left(q^{j}, y^{j}, I^{j}\right)$ remaining unchanged, the $j$-type's demand for $d$ does not change either. Consequently, the changes in $b^{j}$ imply, from the money injection constraint (27), that

$$
\pi^{h} d b^{h}+\pi^{\ell} d b^{\ell}=\frac{\theta}{1+g}\left(\pi^{\ell} \gamma^{\ell} d d^{\ell}+\pi^{h} \gamma^{h} d d^{h}\right)=0 .
$$

Third, with $d^{j}$ unchanged, the only change in the government's revenue requirement comes from the changes in $z^{j}$. Hence, from the steady-state version of (20) and (30),

$$
d R=-\left(\pi^{h} d z^{h}+\pi^{\ell} d z^{\ell}\right)=\pi^{h} d b^{h}+\pi^{\ell} d b^{\ell}=0
$$

This shows that the considered changes satisfy all the constraints that the economy faces but leaves every agent as well off as he was before and completes the proof of part (i) of the Proposition. 
Turning to part (ii) of the Proposition, now start from any initial value for $\theta$ and change the monetary growth rate by $d \theta$. To determine how this changes $q^{j}$, substitute for $i$ from (24) in (25) to get

$$
q^{j}=\frac{1}{1+r}+\gamma^{j}\left(\frac{1}{1+g}-\frac{1}{1+r}\right)+\frac{\tau}{1+r}+\frac{\gamma^{j} \theta}{1+g} .
$$

It follows from (31) that $d q^{j} \equiv\left[\gamma^{j} /(1+r)\right] d \theta$. It is then clear that, because of different values of $\gamma^{j}$, a change in $\theta$ changes $q^{j}$ differently for individuals of different types. As long as the government has to tax future goods at the same rate for everyone, it will be impossible to offset the effect of a change in $\theta$ with a change in $\tau$. Consequently, this aspect of monetary policy cannot be neutralized with fiscal policy.

Regarding the monetary distribution rule, it should not be surprising that it can be rendered impotent in the presence of a nonlinear income tax. Specifically, a nonlinear income tax enables the fiscal authority to exert full control on $z$ and therefore, as can be seen from (28), on an agent's aggregate disposable income. Consequently, any agent specific money injection can be offset by the nonlinear income tax. ${ }^{36}$

As to the relevance of the monetary growth rate, our method of proof alerts us to the fact that if the fiscal authority could tax consumption goods at different rates for different individuals, it would be able to offset the change in $q^{j}$ to both individual types. This would require departing from the common assumption in the optimal tax literature that the fiscal authority has information only on anonymous transactions. Instead, one would need to assume that the fiscal authority can observe personal purchases (who purchased how much), so that it can levy nonlinear taxes also in the goods market. Although the information on personal consumption levels is not typically available,

\footnotetext{
${ }^{36}$ This result does not contradict Williamson's (2008) who finds the monetary expansion rule does matter. Nor is the two different results due to the fact that in Williamson's setup, there is no fiscal authority to try to undo what the monetary authority does. The underlying factor is the distinction he makes between the connected and unconnected agents in terms of their access to financial institutions. The impact of this distinction does not show up in $b^{j}$ in our model. Instead, this distinction works through different $\gamma$ 's that the two types face with respect to their cash-in-advance constraints. This, in turn, manifests itself through $q^{j}$ and not $b^{j}$.
} 
for completeness, we have examined its implications in Appendix C. There we show that with nonlinear commodity taxes the FR is optimal as a corner solution under our assumption that $\gamma^{\ell}>\gamma^{h \ell}$.

Finally, notice that, even though Proposition 1 and its proof refer to a steadystate equilibrium, the presented results apply more generally also outside a steady-state and for any pre-reform policy package, even suboptimal ones, that satisfy the set of constraints faced by the policy maker (i.e. the constraints (4), and (20)-(22)). ${ }^{37}$

\section{Optimal tax/monetary policy}

To characterize the optimal tax/monetary policy, using the mechanism design approach, we follow the common practice in the literature and ignore the "upward" incentive constraint, $v^{\ell} \geq v^{\ell h}$; assuming that it is automatically satisfied. ${ }^{38}$ Thus, the only possible binding constraint will be that of the high-skilled agents mimicking low-skilled agents. Intuitively, this implies that we are concerned only with the realistic case of redistribution from the high-skilled to the low-skilled agents. Focusing on the steadystate equilibrium, the mechanism designer's problem can then be represented as:

$$
\max _{I^{j}, z^{j}, b^{j}, \tau, \theta} \sum_{j=\ell, h} \delta^{j} v\left(q^{j}, y^{j}, \frac{I^{j}}{w^{j}}\right),
$$

subject to the government's budget constraint,

$$
\sum_{j=\ell, h} \pi^{j}\left(I^{j}-z^{j}+\frac{\tau}{1+r} d^{j}\right) \geq \bar{R},
$$

\footnotetext{
${ }^{37}$ Relaxing the assumption of a steady-state equilibrium would not alter the structure of the required proof; it would only require a more cumbersome notation to take into account the time indices.

${ }^{38}$ Given the perfect correlation between skills and financial sophistication, the properties of our setting with two sources of heterogeneity reduces to that of a two-group model à la Stiglitz (1982). In particular, the single-crossing property for the preference structure $v\left(y^{j}, I^{j} / w^{j} ; q^{j}\right)$ will be satisfied in the usual manner (i.e. by having, at any point in the $(I, y)$-space, the indifference curve of a high-skilled agent to be flatter than the indifference curve of a low-skilled agent - a condition that is guaranteed if the composite commodity $y^{j}$ is normal). Then there will at most be one binding self-selection constraint. Moreover, the single-crossing property and the incentive-compatibility constraint together imply that $I^{h}>I^{\ell}$.
} 
the money injection relationship (27),

$$
\sum_{j=\ell, h} \pi^{j} b^{j}=\frac{\theta}{1+g} \sum_{j=\ell, h} \pi^{j} \gamma^{j} d^{j}
$$

and the IC constraint,

$$
v\left(q^{h}, y^{h}, \frac{I^{h}}{w^{h}}\right) \geq v\left(q^{h \ell}, y^{\ell}, \frac{I^{\ell}}{w^{h}}\right),
$$

where the Greek letters on the right-hand side of each constraint denotes its corresponding Lagrange multiplier. ${ }^{39}$ Finally, there is also the non-negativity of the nominal interest rate constraint, $i \geq 0$. This places, from (24), a lower bound on the feasible value of $\theta$, i.e. $\theta \geq(g-r) /(1+r)$, and can be taken care through the Kuhn-Tucker formulation of the problem.

Given the redundancy of one of the instruments $b^{h}$ and $b^{\ell}$, it is sufficient to carry out our optimization with respect to only $b^{h}$ or $b^{\ell}$. Without loss of generality, we choose $b^{h}$. The mechanism designer then determines $I^{h}, I^{\ell}, z^{h}, z^{\ell}, b^{h}, \tau$ and $\theta$. In turn, consumers determine their demands for consumption goods $c$ and $d$. Let $\widetilde{d}^{j}$ denote the $j$-type's compensated (Hicksian) demand for $d$. The following Proposition, proved in Appendix A, characterizes the optimal policy with respect to $\tau$ and $\theta .^{40}$

Proposition 2 Let $\alpha^{\text {hl }}$ denote the marginal utility of income for the hl-mimicker. At

\footnotetext{
${ }^{39}$ In focusing on the steady-state utilities we are nor suggesting that the welfare of agents on the transition path does not matter. It is just that considering them does not change the points addressed in our paper and makes the presentation more cumbersome. One can also rationalize our approach by assuming a Millian social welfare function over undiscounted average utilities of all present and future generations.

${ }^{40}$ Since our focus lies in assessing whether it is optimal or not to abide by the FR, we omit presenting the expressions characterizing the optimal marginal income tax rates faced by high- and low-skilled agents. These expressions are available upon request.
} 
the solution to the planner's problem, the optimal values for $\tau$ and $\theta$ satisfy:

$$
\begin{aligned}
& \lambda \alpha^{h \ell}\left(d^{h \ell}-d^{\ell}\right)+\mu \sum_{j} \pi^{j}\left(\frac{\tau}{1+r}+\frac{\theta \gamma^{j}}{1+g}\right) \frac{\partial \widetilde{d}^{j}}{\partial q^{j}}=0, \\
& \lambda \alpha^{h \ell}\left(\gamma^{h \ell} d^{h \ell}-\gamma^{\ell} d^{\ell}\right)+\mu \sum_{j} \pi^{j}\left(\frac{\tau}{1+r}+\frac{\theta \gamma^{j}}{1+g}\right) \gamma^{j} \frac{\partial \widetilde{d}^{j}}{\partial q^{j}} \leq 0,
\end{aligned}
$$

where (33) is satisfied as a strict equality if $\theta>(g-r) /(1+r)$.

Eq. (32) and inequality (33) implicitly characterize the optimal values for $\tau$ and $\theta$ by means of a trade-off between two effects arising, respectively, from a compensated marginal increase in $\tau$ and $\theta .^{41}$ One is the effects on the IC constraint, represented by the $\lambda$-terms, and the other is public budget effects, represented by the $\mu$-terms. ${ }^{42}$ In particular, the $\lambda$-term in (32) shows that a marginal increase in $\tau$, coupled with an offsetting change in the nonlinear income tax schedule aimed at leaving unchanged the utility of low-skilled agents, will adversely affect the utility of a mimicker, and therefore weaken the IC constraint, when $d^{h \ell}>d^{\ell}$. Instead, the $\lambda$-term in (33) shows that a marginal increase in $\theta$, coupled with an offsetting change in the nonlinear income tax schedule aimed at leaving unchanged the utility of low-skilled agents, will make a mimicker worse off, and therefore weaken the IC constraint, when $\gamma^{h \ell} d^{h \ell}>\gamma^{\ell} d^{\ell}$.

We are now is a position to examine the optimality of the FR. To emphasize the role played by financial connectedness, we shall first examine a setting without differences in financial connectedness. This requires that two conditions are jointly satisfied: i) there

\footnotetext{
${ }^{41} \mathrm{~A}$ compensated marginal increase in $\tau$ (or $\theta$ ) is defined as an increase in $\tau$ (or $\theta$ ) accompanied by an offsetting change in the nonlinear income tax schedule such that the well-being of every non-mimicking agents is left unaffected. Formally, this requires adjusting $z^{j}$ by $d z^{j}=d^{j} /(1+r)$ when $\tau$ is marginally raised and by $d z^{j}=\gamma^{j} d^{j} /(1+g)$ when $\theta$ is marginally raised.

${ }^{42}$ In reality, part of the $\mu$-terms in (32)-(33) capture effects on the money-injection constraint. However, due to the fact that an optimizing planner always chooses the policy instruments in such a way as to achieve $\mu=-\eta$ (see the proof of Proposition 2 in Appendix A for details), one can re-interpret the effect on the money-injection constraint as a public-budget effect. The fact that $\mu=-\eta$ tells us that at a social optimum the planner is indifferent between raising the utility of type $j$-agents via a marginal increase in $z^{j}$ or via a marginal increase in $b^{j}$. This is due to the fact that, at the individual level, the marginal rate of substitution between $z^{j}$ and $b^{j}$ is one; see equation (28).
} 
is no underlying heterogeneity in financial sophistication among agents and ii) financial connectedness does not depend on an agent's income.

\section{The FR without differences in financial connectedness}

Absent differences in financial connectedness, $\gamma^{h}=\gamma^{\ell}=\gamma^{h \ell} \equiv \gamma$. It then follows immediately from Proposition 2 that the optimal values of $\theta$ and $\tau$ are characterized by one single relationship:

$$
\frac{\tau}{1+r}+\frac{\theta \gamma}{1+g}=\frac{\lambda \alpha^{h \ell}\left(d^{\ell}-d^{h \ell}\right)}{\mu \sum_{j} \pi^{j} \frac{\partial \widetilde{d}^{j}}{\partial q^{j}}} .
$$

This tells us that the optimal monetary growth rate is not unique. Social welfare is maximized by a continuum of values for the monetary growth rate, $\theta$, and the tax on the second-period consumption, $\tau$ (coupled with supporting income tax rates).

The intuition for this result comes from our earlier discussion on the redistributive implications of the rate of money growth. If $\gamma^{h}=\gamma^{\ell}=\gamma^{h \ell} \equiv \gamma$, the intertemporal prices are the same across agents. Thus, by properly changing $\tau$ the fiscal authority can undo for all agents any effect on $q$ induced by a change in $\theta$. More precisely (see Appendix A for details), for any change in the money-injection rate one can always find a feasible adjustment in the tax rate on second-period consumption and the nonlinear income tax that leaves everybody's welfare intact. An implication of this is that the optimal monetary growth rate is not unique; a continuum of values satisfies it.

From the result above it also descends that, absent commodity taxation, one can escape the instrument over-determination. Without $\tau$ as a control variable, the fiscal authority cannot neutralize the redistributive effects of monetary growth rate. One can then ask if in this case the FR is desirable. With $\tau$ constrained to be equal to zero, the government's optimization problem discussed in Section 4 is modified slightly. Specifically, exclude $\tau$ from the set of policy instruments but otherwise keep the problem 
unchanged. This results in a characterization of optimal $\theta$ given by: ${ }^{43}$

$$
\theta \geq \frac{\lambda(1+g) \alpha^{h \ell}}{\mu \gamma\left(-\sum_{j} \pi^{j} \frac{\partial \widetilde{d}^{j}}{\partial q^{j}}\right)}\left(d^{h \ell}-d^{\ell}\right),
$$

where (34) is satisfied as an equality if its right-hand side is greater than $(g-r) /(1+r)$; otherwise $\theta=0$.

Assume now that the golden rule condition $r=g$ is satisfied. ${ }^{44}$ From (24), this means that $\theta=i$. Under this circumstance the optimality of the $\mathrm{FR}, i=0$, is the same thing as the optimality of $\theta=0$. It then follows from (34) that we will have the FR satisfied as an interior solution if $d^{h \ell}=d^{\ell}$ and as a corner solution if $d^{h \ell}<d^{\ell}$. The first case arises if preferences are weakly-separable in labor supply and goods. ${ }^{45}$ This is of course a manifestation of the Atkinson-Stiglitz (1976) theorem. The second case arises if labor supply and second-period consumption are complements so that $d^{h \ell}<d^{\ell}$. Intuitively, a higher inflation rate imposes on agents a utility loss that is proportional to $\gamma d$; thus, absent differences in financial connectedness, $d^{h \ell}<d^{\ell}$ implies that a higher inflation rate hurts a low-skilled agent more than a high-skilled mimicker, and therefore is of no help in relaxing the IC constraint.

These results correspond to da Costa and Werning's (2008). In the latter paper, the complementarity assumption concerned labor supply and real balances. However, given

\footnotetext{
${ }^{43}$ The optimization problem continues to be summarized by the Lagrangian (A1), but the optimization is carried out with respect to $I^{h}, I^{\ell}, z^{h}, z^{\ell}, b^{h}$, and $\theta$. Consequently, eq. (A7) disappears from the set of first-order conditions (A2)-(A9); the rest of the equations remain as previously. This means that eq. (A22), and with it eq. (A24), disappear. On the other hand, (A23) and thus (A25) remain. To sum up, relationship (33) applies but in a simplified version with $\gamma^{h}=\gamma^{\ell}=\gamma^{h \ell}$ and $\tau=0$.

${ }^{44}$ As discussed in the introduction, in OLG models one can always exploit the difference between the real interest rate and the population growth rate to raise the steady-state welfare through intergenerational wealth transfers. Distortionary commodity taxes achieve this. An inflation tax, is one such mechanism. Yet, this reason for the suboptimality of the FR has nothing to do with the heterogeneity of agents or with the existence of Mirrleesian taxes. Thus, to avoid distraction caused by this obvious source of suboptimality, hereafter we assume that the economy is at the golden rule.

${ }^{45}$ This follows from the fact that with weakly-separable preferences, the $h$-type who pretends to be an $\ell$-type and the $\ell$-type have identical after-tax incomes and identical marginal rates of substitution between goods (independent of leisure). They also face the same prices for all goods including $d$ (because $\left.\gamma^{\ell}=\gamma^{h \ell}\right)$.
} 
that in our cash-in-advance constraint model, real balances are proportional to secondperiod consumption expenditures, the two assumptions amount to the same thing. The crucial point though is that the assumption is somewhat forced and unwarranted in our model. Proposition 3 summarizes the results of this section.

Proposition 3 Assume that differential productivities are the only source of heterogeneity and that financial connectedness does not depend on earned income, so that $\gamma^{h}=\gamma^{\ell}=\gamma^{h \ell}=\gamma$. In the steady-state equilibrium:

(i) The fiscal authority is able to neutralize the effects of a change in $\theta$. Under this circumstance, the optimal monetary growth rate is not unique.

(ii) Set $\tau=0$. At the golden rule, the optimal value of $\theta=i$ is characterized by relationship (34). Then:

(a) If preferences are weakly-separable in labor supply and goods, so that $d^{\text {hl }}=d^{\ell}$, the FR is satisfied as an interior solution.

(b) If labor supply and second-period consumption are complements, so that $d^{h \ell}<d^{\ell}$, the FR is satisfied as a corner solution.

(c) If labor supply and second-period consumption are substitutes, so that $d^{\text {hl}}>d^{\ell}$, the FR is violated.

\section{The FR with differences in financial connectedness}

We now turn to examining the optimality of the FR when allowing for differences in financial connectedness. As a basis for the discussion, Lemma 1, proved in Appendix A, provides a characterization for the optimal $\tau$ and the optimal $\theta$. 
Lemma 1 Let:

$$
\begin{gathered}
\Gamma \equiv \mu\left(\gamma^{\ell}-\gamma^{h}\right)^{2} \pi^{\ell} \pi^{h} \frac{\partial \widetilde{d}^{\ell}}{\partial q^{\ell}} \frac{\partial \widetilde{d}^{h}}{\partial q^{h}}>0, \\
\Psi \equiv\left(\gamma^{h \ell} d^{h \ell}-\gamma^{\ell} d^{\ell}\right) \underbrace{\left(-\sum_{j} \pi^{j} \frac{\partial \widetilde{d}^{j}}{\partial q^{j}}\right)}_{>0}-\left(d^{h \ell}-d^{\ell}\right) \underbrace{\left(-\sum_{j} \pi^{j} \gamma^{j} \frac{\partial \widetilde{d^{j}}}{\partial q^{j}}\right)}_{>0}, \\
\Phi \equiv\left(\gamma^{h \ell} d^{h \ell}-\gamma^{\ell} d^{\ell}\right) \underbrace{\left(\sum_{j} \pi^{j} \gamma^{j} \frac{\partial \widetilde{d}^{j}}{\partial q^{j}}\right)}_{<0}-\left(d^{h \ell}-d^{\ell}\right) \underbrace{\left(\sum_{j} \pi^{j}\left(\gamma^{j}\right)^{2} \frac{\partial \widetilde{d}^{j}}{\partial q^{j}}\right)}_{<0} .
\end{gathered}
$$

where the indicated signs come from the fact that, with $\widetilde{d^{j}}, j=h, \ell$ denoting compensated demand, $\partial \widetilde{d}^{j} / \partial q^{j}<0$. Then, at the golden rule when $r=g$ :

$$
\begin{aligned}
& \theta=(1 / \Gamma)(1+r) \lambda \alpha^{h \ell} \Psi \\
& \tau=(1 / \Gamma)(1+r) \lambda \alpha^{h \ell} \Phi
\end{aligned}
$$

if the constraint $\theta=i \geq 0$ is non-binding; otherwise, with a binding constraint, one has a corner solution for $\theta$ with,

$$
\begin{aligned}
& \theta=0 \\
& \tau=\frac{\lambda(1+r) \alpha^{h \ell}}{\mu\left(-\sum_{j} \pi^{j} \frac{\partial \widetilde{d}^{j}}{\partial q^{j}}\right)}\left(d^{h \ell}-d^{\ell}\right) .
\end{aligned}
$$

As explained at the end of Section 2.1, building on Williamson's (2008) contribution, we regard financial connectedness as being jointly determined by the income earned by a given individual and by his inherent degree of financial sophistication, interpreted as an individual characteristic distinct from earning ability but positively correlated with it. With $\gamma^{\ell}(I)>\gamma^{h}(I)$ and $\gamma^{j}(I)$ decreasing in $I$, and considering that in equilibrium $I^{\ell}<I^{h}$ (see footnote 38), it then immediately follows that $\gamma^{\ell} \equiv \gamma^{\ell}\left(I^{\ell}\right)>\gamma^{h}\left(I^{h}\right) \equiv \gamma^{h}$. When it comes to $\gamma^{h \ell}$, we have the more-productive $h$-type person earning $I^{\ell}$, the lower 
income of the less-productive $\ell$-type person. The two properties of $\gamma^{j}(I), j=\ell, h$, then imply that, $\gamma^{\ell}\left(I^{\ell}\right)>\gamma^{h}\left(I^{\ell}\right)>\gamma^{h}\left(I^{h}\right)$, i.e.,

$$
\gamma^{\ell}>\gamma^{h \ell}>\gamma^{h}
$$

Armed with Lemma 1, and in light of condition (42), we are now in a position to examine the optimality of the FR when financial connectedness matters.

Proposition 4 Assume individuals differ in productivities as well as in financial connectedness with $\gamma^{\ell}>\gamma^{h \ell}>\gamma^{h}$. In the golden rule steady-state equilibrium:

(a) If labor supply and second-period consumption are non-substitutes, so that $d^{\text {hl }} \leqslant$ $d^{\ell}$, the FR is satisfied as a corner solution.

(b) If labor supply and second-period consumption are substitutes, so that $d^{\text {hl }}>d^{\ell}$, the FR may or may not be violated. Specifically, if $\gamma^{h \ell} d^{h \ell}-\gamma^{\ell} d^{\ell} \leq 0$, then the FR is again satisfied as a corner solution. On the other hand, if $\gamma^{h \ell} d^{\text {hl }}-\gamma^{\ell} d^{\ell}>0$, the FR may be satisfied as well as being violated.

Proof. To prove (a), rewrite $\Psi$ given by (36) as

$$
\begin{aligned}
\Psi & \equiv\left(\gamma^{\ell} d^{\ell}-\gamma^{h \ell} d^{h \ell}\right)\left(\pi^{\ell} \frac{\partial \widetilde{d}^{\ell}}{\partial q^{\ell}}+\pi^{h} \frac{\partial \widetilde{d}^{h}}{\partial q^{h}}\right)-\left(d^{\ell}-d^{h \ell}\right)\left(\pi^{\ell} \gamma^{\ell} \frac{\partial \widetilde{d}^{\ell}}{\partial q^{\ell}}+\pi^{h} \gamma^{h} \frac{\partial \widetilde{d^{h}}}{\partial q^{h}}\right) \\
& =\left(\gamma^{\ell}-\gamma^{h \ell}\right) \pi^{\ell} d^{h \ell} \frac{\partial \widetilde{d}^{\ell}}{\partial q^{\ell}}+\left[\left(\gamma^{\ell}-\gamma^{h}\right) d^{\ell}-\left(\gamma^{h \ell}-\gamma^{h}\right) d^{h \ell}\right] \pi^{h} \frac{\partial \widetilde{d^{h}}}{\partial q^{h}} .
\end{aligned}
$$

Now $\gamma^{\ell}>\gamma^{h \ell} \Rightarrow\left(\gamma^{\ell}-\gamma^{h}\right)>\left(\gamma^{h \ell}-\gamma^{h}\right)$. Consequently, with $d^{h \ell} \leqslant d^{\ell},\left[\left(\gamma^{\ell}-\gamma^{h}\right) d^{\ell}\right.$ $\left.-\left(\gamma^{h \ell}-\gamma^{h}\right) d^{h \ell}\right]>0$ and $\Psi<0$. Hence, from Lemma 1, we have a corner solution for $\theta$.

To prove (b), consider the expression for $\Psi$ in (36). With $d^{h \ell}>d^{\ell}$, if $\gamma^{h \ell} d^{h \ell}-\gamma^{\ell} d^{\ell} \leqslant 0$ then $\Psi<0$, and hence from Lemma 1, we have a corner solution for $\theta$. On the other hand, if $\gamma^{h \ell} d^{h \ell}-\gamma^{\ell} d^{\ell}>0, \Psi$ can take a positive value so that the FR is violated; but it can also take a non-positive value implying that the FR is satisfied. This is shown through numerical examples in Appendix B. 
To shed light on the results of Proposition 4, observe first that in general one wants to use both instruments $\theta$ and $\tau$; each has its own advantage. This is best seen by considering the optimal allocation that results under a general income tax when both $\tau$ and $\theta$ are constrained to be zero. Then note the effect on the IC constraint of a compensated increase in $\theta$, i.e. the effect of introducing an inflation tax coupled with an offsetting change in the nonlinear income tax schedule aimed at leaving unchanged the utility of all non-mimicking agents. This requires supplementing $d \theta>0$ with $d z^{\ell}=$ $\frac{\gamma^{\ell} d^{\ell}}{1+g} d \theta$ and $d z^{h}=\frac{\gamma^{h} d^{h}}{1+g} d \theta$. For the reform to make the mimicker worse off, and therefore relax the IC constraint, it must be that $\gamma^{h \ell} d^{h \ell}>\gamma^{\ell} d^{\ell}$. With $\gamma^{\ell}>\gamma^{h \ell}$, this represents a stronger condition than $d^{h \ell}>d^{\ell}$, which is the condition required for a compensated increase in $\tau$ to relax the IC constraint (the considered reform package would be in this case $d \tau>0$ coupled with $d z^{\ell}=\frac{d^{\ell}}{1+r} d \tau$ and $\left.d z^{h}=\frac{d^{h}}{1+r} d \tau\right)$. The reason why we get a more demanding condition is that an increase in $\tau$ raises $q^{\ell}$ and $q^{h \ell}$ uniformly, whereas an increase in $\theta$ has the unattractive feature of raising $q^{\ell}$ more than $q^{h \ell}$. This aspect represents an advantage of acting on $\tau$, rather than violating the FR, as an instrument to relax the IC constraint. At the same time, while $\tau$ necessarily distorts $q^{\ell}$ and $q^{h}$ to the same extent, an inflation tax can generate any intended upward distortion on $q^{\ell}$ (intended for the purpose of relaxing the IC constraint) with a smaller distortion on $q^{h}$ (because $\gamma^{\ell}>\gamma^{h}$ ). Given that any distortion on $q^{h}$ constitutes a pure efficiency loss (without benefits in terms of relaxing the IC constraint), this aspect explains why, when $\gamma^{h \ell} d^{h \ell}>\gamma^{\ell} d^{\ell}$, it might be desirable to violate the FR rather than to raise $\tau$, and this despite the fact that violating the FR determines a regressive profile of second-period consumption taxes.

Yet, whereas $\tau$ can freely take either a positive or a negative value, this is not the case with $\theta$ which faces a lower bound of zero. This constraint on $\theta$ implies that the FR can only be violated if the required distortion is to set $\theta$ at a positive value. Now when $d^{h \ell} \leq d^{\ell}$, the distortion requires setting a negative value for $\theta$; hence satisfaction 
of the FR as a corner solution. The same is true with $d^{h \ell}>d^{\ell}$ and $\gamma^{h \ell} d^{h \ell}-\gamma^{\ell} d^{\ell} \leqslant 0$. On the other hand, with $\gamma^{h \ell} d^{h \ell}-\gamma^{\ell} d^{\ell}>0$, the distortion can go either way resulting in the possibility of the FR being violated.

To summarize, when $\gamma^{h \ell} d^{h \ell}-\gamma^{\ell} d^{\ell}>0$ both a commodity tax on second-period consumption and an inflation tax can be used as instruments to relax the binding IC constraint. However, by distorting the intertemporal price of consumption, these policy instruments entail an efficiency cost in terms of foregone revenue due to substitution effects. Of the two instruments, while a commodity tax is more effective as a mimickingdeterring device, it also entails a larger efficiency cost. ${ }^{46}$ Thus, when the latter effect dominates, an inflation tax will be part of the optimal policy.

The comparison between the results of Proposition 4 with our earlier results in Proposition 3 is illuminating. With or without differences in financial connectedness, the FR holds if $d^{h \ell} \leq d^{\ell}$. On the other hand, whereas $d^{h \ell}>d^{\ell}$ necessarily results in the violation of the $\mathrm{FR}$ in the absence of differences in financial connectedness, this is not the case when financial connectedness differs. Indeed, if $d^{h \ell}>d^{\ell}$ but $\gamma^{h \ell} d^{h \ell}-\gamma^{\ell} d^{\ell} \leqslant 0$, the FR continues to be satisfied as a corner solution. And even if $\gamma^{h \ell} d^{h \ell}-\gamma^{\ell} d^{\ell}>0$, the FR can still hold. Put differently, financial connectedness makes the case for the FR stronger, limiting the possibilities for its violation. At the same, it does not require to impose arbitrary assumptions on the structure of preferences - as the condition $d^{h \ell} \leq d^{\ell}$ in the absence of differences in financial connectedness - to ensure that it always holds.

\footnotetext{
${ }^{46}$ This is apparent by looking at eqs. (32)-(33) in Proposition 1 which implicitly provide the optimal values for $\tau$ and $\theta$. In each equation, the $\lambda$-term captures a mimicking deterring effect and the $\mu$-term a public budget effect due to substitution effects from changing the intertemporal price of consumption. In eq. (32) the effects are those arising from a marginal compensated increase in $\tau$, whereas in (33) the effects are those arising from a marginal compensated increase in $\theta$. When $\gamma^{h \ell} d^{h \ell}-\gamma^{\ell} d^{\ell}>0$ we have that both the $\lambda$-term in (32) and the one in (33) take a positive sign, indicating that both a marginal compensated increase in $\tau$ and a marginal compensated increase in $\theta$ deliver gains in terms of mimicking-deterring effects. However, since $(0<) \gamma^{h \ell}<\gamma^{\ell}(\leq 1)$, we have that the gains generated by acting on $\tau$ are larger than those generated by raising $\theta$. On the other hand, comparing the $\mu$-terms in (32) and (33), which represent the efficiency cost (in terms of foregone revenue) due to the substitution effects induced by distorting the intertemporal price of consumption, we can see that the term appearing in (33) is smaller (in absolute value) than the one in (32).
} 
Finally, observe that the source of financial connectedness also plays a role in the results. To see this, consider two limit cases: (i) differences in financial connectedness are only due to an underlying heterogeneity in financial sophistication among agents (earned income plays no role in itself); (ii) differences in financial connectedness are only due to differences in earned income (no underlying heterogeneity in financial sophistication among agents). ${ }^{47}$ Under (i), $\gamma^{h \ell}=\gamma^{h}<\gamma^{\ell}$ which simplifies (43) to

$$
\Psi=\underbrace{\left(\gamma^{\ell}-\gamma^{h}\right)}_{>0} \underbrace{\left(\pi^{\ell} d^{h \ell} \frac{\partial \widetilde{d}^{\ell}}{\partial q^{\ell}}+\pi^{h} d^{\ell} \frac{\partial \widetilde{d}^{h}}{\partial q^{h}}\right)}_{<0}<0 .
$$

Consequently, in this limit case, the FR is always optimal as a corner solution, and the optimal value for $\tau$ is determined according to eq. (41), and therefore $\operatorname{sign}(\tau)=$ $\operatorname{sign}\left(d^{h \ell}-d^{\ell}\right)$. Under (ii), $\gamma^{h \ell}=\gamma^{\ell}>\gamma^{h}$ simplifying (43) to

$$
\Psi=\left(d^{h \ell}-d^{\ell}\right) \underbrace{\left(\gamma^{\ell}-\gamma^{h}\right)}_{>0} \underbrace{\left(-\pi^{h} \frac{\partial \widetilde{d}^{h}}{\partial q^{h}}\right)}_{>0},
$$

and therefore $\operatorname{sign}(\Psi)=\operatorname{sign}\left(d^{h \ell}-d^{\ell}\right)$, implying that it will be desirable to violate the FR if $d^{h \ell}>d^{\ell}$. When this happens, the optimal value for $\tau$ is determined according to $(39)$ and $\operatorname{sign}(\tau)=\operatorname{sign}(\Phi)$. With $\gamma^{h \ell}=\gamma^{\ell}$, (37) simplifies to

$$
\Phi=\left(d^{h \ell}-d^{\ell}\right) \underbrace{\left(\gamma^{\ell}-\gamma^{h}\right)}_{>0} \underbrace{\pi^{h} \gamma^{h} \frac{\partial \widetilde{d}^{h}}{\partial q^{h}}}_{<0}
$$

which implies that $\operatorname{sign}(\Phi)=\operatorname{sign}\left(d^{\ell}-d^{h \ell}\right)$, and therefore $\tau<0 .{ }^{48}$

\footnotetext{
${ }^{47}$ In the second case agents are only heterogeneous along one innate characteristic (earning ability), although in equilibrium, since high-skilled agents earn more than low-skilled agents, the former end up being more financially connected than the latter.

${ }^{48}$ Notice that the optima $\tau$ can never be positive when $\gamma^{h \ell}=\gamma^{\ell}$. We have in fact already established that $\tau<0$ when $d^{h \ell}>d^{\ell}$. On the other hand, if it were the case that $d^{h \ell} \leq d^{\ell}$, the FR would be satisfied and $\operatorname{sign}(\tau)=\operatorname{sign}\left(d^{h \ell}-d^{\ell}\right)$.
} 
Finally, notice that, leaving aside the limit case when $\gamma^{h \ell}=\gamma^{\ell}$, it is not necessarily true that one should have $\tau<0$ when it is desirable to violate the FR. This can be easily seen by rewriting the expression for $\Phi$ given by (37) as

$$
\Phi \equiv\left(\gamma^{h \ell}-\gamma^{\ell}\right) \pi^{\ell} \gamma^{\ell} d^{h \ell} \frac{\partial \widetilde{d}^{\ell}}{\partial q^{\ell}}+\left[\left(\gamma^{h}-\gamma^{\ell}\right) d^{\ell}-\left(\gamma^{h}-\gamma^{h \ell}\right) d^{h \ell}\right] \pi^{h} \gamma^{h} \frac{\partial \widetilde{d}^{h}}{\partial q^{h}}
$$

and noticing that $\partial \Phi / \partial \gamma^{h \ell}=d^{h \ell} \sum_{j=\ell, h} \pi^{j} \gamma^{j} \frac{\partial \widetilde{d}^{j}}{\partial q^{j}}<0$. Thus, as $\gamma^{h \ell}$ lowers, $\Phi$ increases, implying that the optimal $\tau$ can either be positive or negative when it is desirable to violate the FR.

\section{Summary and conclusion}

This paper has modeled an OLG economy à la Samuelson (1958) with money wherein cash holdings are rationalized by a version of the Clower cash-in-advance constraint. A distinguishing feature of the model is that it has allowed for agents to differ both in terms of labor productivity and in terms of financial connectedness. Some agents are more skilled and more financially connected than others. This means that they not only have a higher earning ability, but also require a proportionately smaller cash reserve to mediate their expenditures. Money supply increases, or contracts, at a fixed rate per year through lump-sum money transfers to individuals. The government has information on individuals' incomes and anonymous expenditures; allowing it to levy nonlinear income and linear commodity taxes. Within this framework, the paper has studied the nature of the economy's equilibrium as well as its steady state. It has also characterized the informationally constrained Pareto-efficient allocations of this economy, and has investigated if these allocations satisfy the FR.

The paper has established a link between optimal monetary policy and the reach of fiscal authority's tax instruments. It has found that Mirrleesian taxes can fully neutralize the redistributive effects of monetary policy only if agents do not differ in 
financial connectedness. In this case, there will exist instrument "over-determination". That is, the optimal monetary growth rate is not unique; a continuum of values satisfies it (supported by offsetting tax instruments).

With differences in financial connectedness, the over-determinacy disappears and the optimal policy is characterized by a unique commodity tax rate and a unique monetary growth rate. It also results in the FR being quite robust without having to impose arbitrary assumptions on the structure of preferences (though almost always as a corner solution). Yet if labor supply and second-period consumption are substitutes, it might be optimal to violate the FR, and this despite the fact that the government aims at redistributing from the high-skilled agents to the low-skilled agents and the fact that violating the FR determines a regressive profile of second-period consumption taxes. However, for the FR to be violated, substitutability between labor supply and secondperiod consumption is not a sufficient condition; one also needs that the differences in financial connectedness are to a sufficiently large extent explained by differences in income rather than by an underlying heterogeneity in financial sophistication (interpreted as an individual characteristic correlated with earning ability but distinct from it).

The intuition for this result comes from the fact that, even when an inflation tax can help relaxing the binding incentive-compatibility constraint faced by the government in the design of the income tax schedule, a commodity tax represents a more powerful instrument for mimicking-deterring purposes. On the other hand, the efficiency costs (in terms of foregone revenue for the government) due to the substitution effects are lower when the intertemporal price of consumption is distorted through an inflation tax rather than through a commodity tax. When the latter effects dominates, which happens when the differences in financial connectedness are to a sufficiently large extent explained by differences in income rather than by an underlying heterogeneity in financial sophistication, violating the FR becomes desirable.

To conclude, we should emphasize that the paper has completely ignored the macro- 
economic issues associated with monetary and fiscal policies. Questions such as stabilization, unemployment, sticky prices, and the like have not been touched in this study not because they are unimportant, but simply because they are outside the purview of the current study. ${ }^{49}$

\footnotetext{
${ }^{49}$ Some of these issues are discussed by Correia et al. (2008) in a dynamic Ramsey setting. They show that sticky prices are irrelevant for the conduct of monetary policy if fiscal instruments are not restricted.
} 


\section{Appendix A}

Proof of Proposition 2: Using $v^{j}$ to denote $v\left(q^{j}, y^{j}, I^{j} / w^{j}\right)$ and $v^{j k}$ to denote $v\left(q^{j k}, y^{k}, I^{k} / w^{j}\right)$, the mechanism designer's problem can be summarized by means of the Kuhn-Tucker Lagrangian:

$$
\begin{aligned}
\mathcal{L} & =\sum_{j=\ell, h} \delta^{j} v^{j}+\mu\left[\sum_{j=\ell, h} \pi^{j}\left(I^{j}-z^{j}+\frac{\tau}{1+r} d^{j}\right)-\bar{R}\right] \\
& +\eta \sum_{j=\ell, h} \pi^{j}\left(b^{j}-\frac{\theta}{1+g} \gamma^{j} d^{j}\right)+\lambda\left(v^{h}-v^{h \ell}\right),
\end{aligned}
$$

with the non-negativity constraint $\theta-\frac{g-r}{1+r} \geq 0$. The first-order conditions associated with Lagrangian (A1) are:

$$
\begin{aligned}
\frac{\partial \mathcal{L}}{\partial I^{h}} & =\left(\delta^{h}+\lambda\right)\left(\frac{\partial v^{h}}{\partial I^{h}}+\frac{\partial v^{h}}{\partial q^{h}} \frac{\partial q^{h}}{\partial \gamma^{h}} \frac{\partial \gamma^{h}}{\partial I^{h}}\right)+\mu \pi^{h}\left[1+\frac{\tau}{1+r}\left(\frac{\partial d^{h}}{\partial I^{h}}+\frac{\partial d^{h}}{\partial q^{h}} \frac{\partial q^{h}}{\partial \gamma^{h}} \frac{\partial \gamma^{h}}{\partial I^{h}}\right)\right] \\
& -\eta \frac{\theta \pi^{h}}{1+g}\left[\gamma^{h} \frac{\partial d^{h}}{\partial I^{h}}+\left(\gamma^{h} \frac{\partial d^{h}}{\partial q^{h}} \frac{\partial q^{h}}{\partial \gamma^{h}}+d^{h}\right) \frac{\partial \gamma^{h}}{\partial I^{h}}\right] \\
& =0, \\
\frac{\partial \mathcal{L}}{\partial I^{\ell}} & =\delta^{\ell}\left(\frac{\partial v^{\ell}}{\partial I^{\ell}}+\frac{\partial v^{\ell}}{\partial q^{\ell}} \frac{\partial q^{\ell}}{\partial \gamma^{\ell}} \frac{\partial \gamma^{\ell}}{\partial I^{\ell}}\right)-\lambda\left(\frac{\partial v^{h \ell}}{\partial I^{\ell}}+\frac{\partial v^{h \ell}}{\partial q^{h \ell}} \frac{\partial q^{h \ell}}{\partial \gamma^{h \ell}} \frac{\partial \gamma^{h \ell}}{\partial I^{\ell}}\right) \\
& +\mu \pi^{\ell}\left[1+\frac{\tau}{1+r}\left(\frac{\partial d^{\ell}}{\partial I^{\ell}}+\frac{\partial d^{\ell}}{\partial q^{\ell}} \frac{\partial q^{\ell}}{\partial \gamma^{\ell}} \frac{\partial \gamma^{\ell}}{\partial I^{\ell}}\right)\right]-\eta \frac{\theta \pi^{\ell}}{1+g}\left[\gamma^{\ell} \frac{\partial d^{\ell}}{\partial I^{\ell}}+\left(\gamma^{\ell} \frac{\partial d^{\ell}}{\partial q^{\ell}} \frac{\partial q^{\ell}}{\partial \gamma^{\ell}}+d^{\ell}\right) \frac{\partial \gamma^{\ell}}{\partial I^{\ell}}\right] \\
& =0, \\
\frac{\partial \mathcal{L}}{\partial z^{h}} & =\left(\delta^{h}+\lambda\right) \frac{\partial v^{h}}{\partial y^{h}}+\mu\left(-\pi^{h}+\frac{\tau \pi^{h}}{1+r} \frac{\partial d^{h}}{\partial y^{h}}\right)-\eta \frac{\gamma^{h} \theta \pi^{h}}{1+g} \frac{\partial d^{h}}{\partial y^{h}}=0, \\
\frac{\partial \mathcal{L}}{\partial z^{\ell}} & =\delta^{\ell} \frac{\partial v^{\ell}}{\partial y^{\ell}}-\lambda \frac{\partial v^{h \ell}}{\partial y^{\ell}}+\mu\left(-\pi^{\ell}+\frac{\tau \pi^{\ell}}{1+r} \frac{\partial d^{\ell}}{\partial y^{\ell}}\right)-\eta \frac{\gamma^{\ell} \theta \pi^{\ell}}{1+g} \frac{\partial d^{\ell}}{\partial y^{\ell}}=0, \\
\frac{\partial \mathcal{L}}{\partial b^{h}} & =\left(\delta^{h}+\lambda\right) \frac{\partial v^{h}}{\partial y^{h}}+\mu \frac{\tau \pi^{h}}{1+r} \frac{\partial d^{h}}{\partial y^{h}}+\eta\left(\pi^{h}-\frac{\gamma^{h} \theta \pi^{h}}{1+g} \frac{\partial d^{h}}{\partial y^{h}}\right)=0, \\
\frac{\partial \mathcal{L}}{\partial \tau} & =\sum_{j} \delta^{j} \frac{\partial v^{j}}{\partial \tau}+\lambda\left(\frac{\partial v^{h}}{\partial \tau}-\frac{\partial v^{h \ell}}{\partial \tau}\right)+\frac{\mu}{1+r} \sum_{j} \pi^{j}\left(d^{j}+\tau \frac{\partial d^{j}}{\partial \tau}\right)-\eta \frac{\theta}{1+g} \sum_{j} \pi^{j} \gamma^{j} \frac{\partial d^{j}}{\partial \tau}=0,
\end{aligned}
$$




$$
\begin{gathered}
\frac{\partial \mathcal{L}}{\partial \theta}=\sum_{j} \delta^{j} \frac{\partial v^{j}}{\partial \theta}+\lambda\left(\frac{\partial v^{h}}{\partial \theta}-\frac{\partial v^{h \ell}}{\partial \theta}\right)-\eta \frac{1}{1+g} \sum_{j} \pi^{j} \gamma^{j}\left(d^{j}+\theta \frac{\partial d^{j}}{\partial \theta}\right) \\
+\frac{\mu \tau}{1+r} \sum_{j} \pi^{j} \frac{\partial d^{j}}{\partial \theta} \leq 0, \\
\left(\theta-\frac{g-r}{1+r}\right) \frac{\partial \mathcal{L}}{\partial \theta}=0,
\end{gathered}
$$

where comparing equation (A4) with (A6) reveals that $\mu=-\eta$.

Now substitute for $i$ from (24) in (29) to get

$$
q^{j k}=\frac{1}{1+r}+\gamma^{j k}\left(\frac{1}{1+g}-\frac{1}{1+r}\right)+\frac{\tau}{1+r}+\frac{\gamma^{j k} \theta}{1+g} .
$$

Differentiate equations (31) and (A10) with respect to $\tau$ and $\theta$ to get

$$
\begin{aligned}
\frac{\partial q^{j}}{\partial \tau} & =\frac{\partial q^{j k}}{\partial \tau}=\frac{1}{1+r}, \\
\frac{\partial q^{j}}{\partial \theta} & =\frac{\gamma^{j}}{1+g}, \\
\frac{\partial q^{j k}}{\partial \theta} & =\frac{\gamma^{j k}}{1+g} .
\end{aligned}
$$

Using $\partial d^{j} / \partial \tau=\left(\partial d^{j} / \partial q^{j}\right)\left(\partial q^{j} / \partial \tau\right)$ and $\partial d^{j} / \partial \theta=\left(\partial d^{j} / \partial q^{j}\right)\left(\partial q^{j} / \partial \theta\right)$, one finds

$$
\begin{aligned}
& \frac{\partial d^{j}}{\partial \tau}=\frac{1}{1+r} \frac{\partial d^{j}}{\partial q^{j}}, \\
& \frac{\partial d^{j}}{\partial \theta}=\frac{\gamma^{j}}{1+g} \frac{\partial d^{j}}{\partial q^{j}}
\end{aligned}
$$

Let $\alpha^{j}$ and $\alpha^{j k}$ denote the $j$ - and $j k$-type agents' marginal utility of income:

$$
\begin{aligned}
\left.\frac{\partial v^{j}}{\partial z^{j}}\right|_{\tau, \theta, b^{j}, I^{j}} & =\left.\frac{\partial v^{j}}{\partial b^{j}}\right|_{\tau, \theta, z^{j}, I^{j}}=\left.\frac{\partial v^{j}}{\partial y^{j}}\right|_{q^{j}, I^{j}} \equiv \alpha^{j}, \\
\left.\frac{\partial v^{j k}}{\partial z^{k}}\right|_{\tau, \theta, b^{k}, I^{k}} & =\left.\frac{\partial v^{j k}}{\partial b^{k}}\right|_{\tau, \theta, z^{k}, I^{k}}=\left.\frac{\partial v^{j k}}{\partial y^{k}}\right|_{q^{j k}, I^{k}} \equiv \alpha^{j k} .
\end{aligned}
$$

Differentiate $v^{j}$ and $v^{j k}$ with respect to $\tau$ and $\theta$. Using equations (A11)-(A13) and 
Roy's identity to simplify these derivatives yields,

$$
\begin{aligned}
\left.\frac{\partial v^{j}}{\partial \tau}\right|_{\theta, b^{j}, z^{j}, I^{j}} & =\left.\left.\frac{\partial v^{j}}{\partial q^{j}}\right|_{y^{j}, I^{j}} \frac{\partial q^{j}}{\partial \tau}\right|_{\theta}=\frac{-\alpha^{j} d^{j}}{1+r}, \\
\left.\frac{\partial v^{j k}}{\partial \tau}\right|_{\theta, b^{k}, z^{k}, I^{k}} & =\left.\left.\frac{\partial v^{j k}}{\partial q^{j k}}\right|_{y^{k}, I^{k}} \frac{\partial q^{j k}}{\partial \tau}\right|_{\theta}=\frac{-\alpha^{j k} d^{j k}}{1+r}, \\
\left.\frac{\partial v^{j}}{\partial \theta}\right|_{\tau, b^{j}, z^{j}, I^{j}} & =\left.\left.\frac{\partial v^{j}}{\partial q^{j}}\right|_{y^{j}, I^{j}} \frac{\partial q^{j}}{\partial \theta}\right|_{\tau}=\frac{-\gamma^{j} \alpha^{j} d^{j}}{1+g}, \\
\left.\frac{\partial v^{j k}}{\partial \theta}\right|_{\tau, b^{k}, z^{k}, I^{k}} & =\left.\left.\frac{\partial v^{j k}}{\partial q^{j k}}\right|_{y^{k}, I^{k}} \frac{\partial q^{j k}}{\partial \theta}\right|_{\tau}=\frac{-\gamma^{j k} \alpha^{j k} d^{j k}}{1+g} .
\end{aligned}
$$

Finally, use the result that $\mu=-\eta$ and equations (A14)-(A19) to simplify and reduce the first-order conditions (A4)-(A5) and (A7)-(A8) into the following equations:

$$
\begin{gathered}
\left(\delta^{h}+\lambda\right) \alpha^{h}+\mu \pi^{h}\left(\frac{\gamma^{h} \theta}{1+g}+\frac{\tau}{1+r}\right) \frac{\partial d^{h}}{\partial y^{h}}-\mu \pi^{h}=0, \\
\delta^{\ell} \alpha^{\ell}-\lambda \alpha^{h \ell}+\mu \pi^{\ell}\left(\frac{\gamma^{\ell} \theta}{1+g}+\frac{\tau}{1+r}\right) \frac{\partial d^{\ell}}{\partial y^{\ell}}-\mu \pi^{\ell}=0, \\
\lambda \alpha^{h \ell} d^{h \ell}-\delta^{\ell} \alpha^{\ell} d^{\ell}-\left(\delta^{h}+\lambda\right) \alpha^{h} d^{h}+\mu \sum_{j} \pi^{j} d^{j} \\
+\mu \sum_{j} \pi^{j}\left(\frac{\theta \gamma^{j}}{1+g}+\frac{\tau}{1+r}\right) \frac{\partial d^{j}}{\partial q^{j}}=0, \\
\lambda \alpha^{h \ell} \gamma^{h \ell} d^{h \ell}-\delta^{\ell} \alpha^{\ell} \gamma^{\ell} d^{\ell}-\left(\delta^{h}+\lambda\right) \alpha^{h} \gamma^{h} d^{h}+\sum_{j} \pi^{j} \gamma^{j} d^{j} \\
+\mu\left(\frac{\theta}{1+g} \sum_{j} \pi^{j}\left(\gamma^{j}\right)^{2} \frac{\partial d^{j}}{\partial q^{j}}+\frac{\tau}{1+r} \sum_{j} \pi^{j} \gamma^{j} \frac{\partial d^{j}}{\partial q^{j}}\right) \leq 0,
\end{gathered}
$$

where (A23) is satisfied as an equality if $\theta>(g-r) /(1+r)$.

Now multiply equation (A20) by $d^{h}$ and equation by (A21) $d^{\ell}$, then add the resulting two equations to (A22) to get $\lambda \alpha^{h \ell}\left(d^{h \ell}-d^{\ell}\right)+\mu\left[\frac{\tau}{1+r} \sum_{j}\left(\pi^{j} \frac{\partial d^{j}}{\partial q^{j}}+\pi^{j} d^{j} \frac{\partial d^{j}}{\partial y^{j}}\right)+\frac{\theta}{1+g} \sum_{j}\left(\pi^{j} \gamma^{j} \frac{\partial d^{j}}{\partial q^{j}}+\pi^{j} \gamma^{j} d^{j} \frac{\partial d^{j}}{\partial y^{j}}\right)\right]=0$. 
Let $\widetilde{d^{j}}$ denote the compensated version of $d^{j}$. Then use the Slutsky equation to rewrite the above equation as (32) in the text.

Then multiply equation (A20) by $\gamma^{h} d^{h}$, and equation (A21) by $\gamma^{\ell} d^{\ell}$, and add the resulting two equations to (A23) to get

$$
\begin{aligned}
& \mu\left[\frac{\tau}{1+r} \sum_{j}\left(\pi^{j} \gamma^{j} \frac{\partial d^{j}}{\partial q^{j}}+\pi^{j} \gamma^{j} d^{j} \frac{\partial d^{j}}{\partial y^{j}}\right)+\frac{\theta}{1+g} \sum_{j}\left(\pi^{j}\left(\gamma^{j}\right)^{2} \frac{\partial d^{j}}{\partial q^{j}}+\pi^{j}\left(\gamma^{j}\right)^{2} d^{j} \frac{\partial d^{j}}{\partial y^{j}}\right)\right] \\
& +\lambda \alpha^{h \ell}\left(\gamma^{h \ell} d^{h \ell}-\gamma^{\ell} d^{\ell}\right) \leq 0,
\end{aligned}
$$

where (A25) is satisfied as an equality if $\theta>(g-r) /(1+r)$. Using the Slutsky equation, one can rewrite (A25) as (33) in the text.

Policy over-determination when there are no differences in financial connectedness: Observe first that with $\gamma^{j}=\gamma$, from $(31), q^{j}$ simplifies to

$$
q=\frac{1}{1+r}+\gamma\left(\frac{1}{1+g}-\frac{1}{1+r}\right)+\frac{\tau}{1+r}+\frac{\gamma \theta}{1+g} .
$$

Consider now, starting from any initial values for $\tau$ and $\theta$, a change in the growth rate of money equal to $d \theta$ while offsetting it with a corresponding change in $\tau$ that keeps $q$ constant. It follows from (A26) that one has to set

$$
d \tau=\frac{1+r}{1+g}(-\gamma d \theta)
$$

in order to have $d q=0$.

Next observe that the change in $\theta$ induces a change in $b^{j}$ as well. As in the Proof of Proposition 1, let the fiscal authority also change $z^{j}$ according to $d z^{j}=-d b^{j}$. This change ensures that $d y^{j}=d z^{j}+d b^{j}=0$. With $d y^{j}=d q^{j}=0$ and no change in $I^{j}$, the instituted changes leave the utility of the $h$-types and the $\ell$-types intact. Observe also that the utility of potential mimickers, the $j k$-agents, remain unaffected as they continue to face the same price and income vector $\left(q, y^{k}, I^{k}\right)$. Consequently, the IC constraints continue to be satisfied. Thus, if the considered changes do not violate the government's 
budget constraint, they constitute a feasible change that leaves every agent just as well off as initially.

To check that the government's budget constraint is not violated, note that with $\left(q, y^{j}, I^{j}\right)$ remaining unchanged, the $j$-type's demand for $d$ does not change either. With $d d^{j}=0$, the change in the government's net tax revenue is, from the steady-state version of $(20)$,

$$
d R=-\left(\pi^{h} d z^{h}+\pi^{\ell} d z^{\ell}\right)+\frac{d \tau}{1+r} \sum_{j} \pi^{j} d^{j} .
$$

Substituting $-d b^{j}$ for $d z^{j}$ and the value of $d \tau$ from (A27) in above, we get

$$
d R=\pi^{h} d b^{h}+\pi^{\ell} d b^{\ell}-\frac{\gamma d \theta}{1+g} \sum_{j} \pi^{j} d^{j}
$$

Now note that the changes in $\theta$ and $b^{j}$ must satisfy the money injection constraint equation (27). Given that $d d^{j}=0$, we have

$$
\pi^{h} d b^{h}+\pi^{\ell} d b^{\ell}=\frac{\gamma \sum_{j} \pi^{j} d^{j}}{1+g} d \theta
$$

Substituting from (A29) into (A28) results in $d R=0$.

Proof of Lemma 1: Write equation (32) and the equality version of (33) in matrix form as

$$
\left(\begin{array}{cc}
\sum_{j} \pi^{j} \frac{\partial \widetilde{d}^{j}}{\partial q^{j}} & \sum_{j} \pi^{j} \gamma^{j} \frac{\partial \widetilde{d}^{j}}{\partial q^{j}} \\
\sum_{j} \pi^{j} \gamma^{j} \frac{\partial \widetilde{d}^{j}}{\partial q^{j}} & \sum_{j} \pi^{j}\left(\gamma^{j}\right)^{2} \frac{\partial \widetilde{d}^{j}}{\partial q^{j}}
\end{array}\right)\left(\begin{array}{c}
\frac{\tau}{1+r} \\
\frac{\theta}{1+g}
\end{array}\right)=\frac{-1}{\mu}\left[\begin{array}{c}
\lambda \alpha^{h \ell}\left(d^{h \ell}-d^{\ell}\right) \\
\lambda \alpha^{h \ell}\left(\gamma^{h \ell} d^{h \ell}-\gamma^{\ell} d^{\ell}\right)
\end{array}\right]
$$

The determinant of the $2 \times 2$ matrix in the left-hand side of (A30) is

$$
\sum_{j} \pi^{j} \frac{\partial \widetilde{d}^{j}}{\partial q^{j}} \sum_{j} \pi^{j}\left(\gamma^{j}\right)^{2} \frac{\partial \widetilde{d}^{j}}{\partial q^{j}}-\left(\sum_{j} \pi^{j} \gamma^{j} \frac{\partial \widetilde{d}^{j}}{\partial q^{j}}\right)^{2}=\pi^{\ell} \pi^{h} \frac{\partial \widetilde{d}^{\ell}}{\partial q^{\ell}} \frac{\partial \widetilde{d}^{h}}{\partial q^{h}}\left(\gamma^{\ell}-\gamma^{h}\right)^{2}
$$

which is positive since $\widetilde{d}^{j}$ denote the $j$-type's compensated (Hicksian) demand for second period consumption, so that $\partial \widetilde{d^{j}} / \partial q^{j}$ represents the own-price substitution effect and is 
therefore negative. Premultiplying (A30) by the inverse of the $2 \times 2$ matrix, and using the notation $\Gamma \equiv \mu \pi^{\ell} \pi^{h} \frac{\partial \widetilde{d}^{\ell}}{\partial q^{\ell}} \frac{\partial \widetilde{d}^{h}}{\partial q^{h}}\left(\gamma^{\ell}-\gamma^{h}\right)^{2}$, yields

$$
\begin{aligned}
\left(\begin{array}{c}
\frac{\tau}{1+r} \\
\frac{\theta}{1+g}
\end{array}\right) & =\frac{-1}{\Gamma}\left(\begin{array}{cc}
\sum_{j} \pi^{j}\left(\gamma^{j}\right)^{2} \frac{\partial \widetilde{d}^{j}}{\partial q^{j}} & -\sum_{j} \pi^{j} \gamma^{j} \frac{\partial \widetilde{d}^{j}}{\partial q^{j}} \\
-\sum_{j} \pi^{j} \gamma^{j} \frac{\partial \widetilde{d}^{j}}{\partial q^{j}} & \sum_{j} \pi^{j} \frac{\partial \widetilde{d}^{j}}{\partial q^{j}}
\end{array}\right)\left[\begin{array}{c}
\lambda \alpha^{h \ell}\left(d^{h \ell}-d^{\ell}\right) \\
\lambda \alpha^{h \ell}\left(\gamma^{h \ell} d^{h \ell}-\gamma^{\ell} d^{\ell}\right)
\end{array}\right] \\
& =\frac{\lambda \alpha^{h \ell}}{\Gamma}\left[\begin{array}{c}
-\left(d^{h \ell}-d^{\ell}\right) \sum_{j} \pi^{j}\left(\gamma^{j}\right)^{2} \frac{\partial \widetilde{d}^{j}}{\partial q^{j}}+\left(\gamma^{h \ell} d^{h \ell}-\gamma^{\ell} d^{\ell}\right) \sum_{j} \pi^{j} \gamma^{j} \frac{\partial \widetilde{d}^{j}}{\partial q^{j}} \\
\left(d^{h \ell}-d^{\ell}\right) \sum_{j} \pi^{j} \gamma^{j} \frac{\partial \widetilde{d}^{j}}{\partial q^{j}}-\left(\gamma^{h \ell} d^{h \ell}-\gamma^{\ell} d^{\ell}\right) \sum_{j} \pi^{j} \frac{\partial \widetilde{d}^{j}}{\partial q^{j}}
\end{array}\right] .
\end{aligned}
$$

Or

$$
\begin{aligned}
& \tau=\frac{(1+r) \lambda \alpha^{h \ell}}{\Gamma} \Phi, \\
& \theta=\frac{(1+g) \lambda \alpha^{h \ell}}{\Gamma} \Psi,
\end{aligned}
$$

which lead to (39)-(38) when $r=g$.

\section{Appendix B: Numerical examples}

Assume we are at a steady state and that skilled and unskilled workers have identical preferences represented by

$$
u=10\left(\ln c+\frac{1}{95} d^{0.95}\right)-\frac{L}{2000}(L+d) .
$$

Observe that in this example $u_{L d}<0$ so that labor supply and future goods are (Edgeworth) substitutes. Further, regarding their cash-in-advance constraints, assume that $\gamma^{j}(I), j=\ell, h$, is decreasing in $I$ with the following structure:

$$
\gamma^{j}(I)=1-\beta^{j} I^{\rho^{j}} / \rho^{j}, \quad \rho^{j} \geq 1, \quad \beta^{j}>0
$$

with $\beta^{\ell}<\beta^{h}$ so that $\gamma^{\ell}(I)>\gamma^{h}(I)$. The government has a (weighted) utilitarian objective function $\sum_{j=\ell, h} \delta^{j} v^{j}$, where $\delta^{j}$ denotes the welfare weights, with $\delta^{\ell}>\delta^{h}$. Set $\pi^{h}=0.6$ and $\pi^{\ell}=0.4$ so that sixty percent of workers are skilled and forty percent unskilled. Their real wage rates, reflecting their productivities, are set equal to $w^{h}=4$ 
and $w^{\ell}=2$. Assume further that $r=g=0.4$ and that $\delta^{h}=0.4$ and $\delta^{\ell}=0.6$. As far as the government's external revenue is concerned, we set $\bar{R}=0$ so that optimal taxes are purely redistributive. Finally, let $\beta^{\ell}=0.00005$, while $\beta^{h}$ and $\rho^{j}$ are allowed to vary.

\section{(i) The FR is violated:}

Set $\rho^{h}=\rho^{\ell}=1.2$ and $\beta^{h}=0.0003$. This yields the following solution for the tax instruments and the rate of monetary growth:

$$
\tau=-0.1610, \quad \theta=i=0.3163, \quad T^{\prime}\left(I^{h}\right)=-0.0228, \quad T^{\prime}\left(I^{\ell}\right)=0.4772 .
$$

Given the money injection rate of $31.63 \%$ and the population growth rate of $40 \%$, one calculates $\varphi=-0.0598$. That is, the price level is falling at a rate of $5.98 \%$ per period. Observe also that the marginal income tax rate faced by skilled workers is non-zero, a result that is due to the presence of other policy instruments besides income taxation. ${ }^{50}$ The policy instruments result in the following values for the arguments of the utility function and real money balances:

$$
\begin{aligned}
& c^{h}=259.035, d^{h}=107.654, L^{h}=100.377, y^{h}=339.770, x^{h}=61.095, b^{h}=6.421, \\
& c^{\ell}=137.996, d^{\ell}=64.980, L^{\ell}=43.021, y^{\ell}=191.486, x^{\ell}=31.306, b^{\ell}=29.253 .
\end{aligned}
$$

Implementing the optimal allocation by the government implies $\gamma^{\ell}=0.9913, \gamma^{h \ell}=$ 0.9476 , and $\gamma^{h}=0.6670 .^{51}$

\footnotetext{
${ }^{50}$ The no-distortion at the top result requires that the labor supply of the top skilled agents, type $h$ in our model, be globally undistorted. When the nonlinear income tax is the only policy instrument, the result requires setting the marginal income tax rate faced by top skilled workers to zero. When additional policy instruments are available, the result requires that the marginal effective tax rate faced by top skilled workers is driven to zero. This in general requires that their marginal income tax rate should not be set to zero (see, for instance, Edwards et al., 1994).

${ }^{51}$ While in this example $\tau<0$, this is not a general result. One can generate examples of both $\tau$ and $\theta$ being positive. For example, setting $\rho^{h}=\rho^{\ell}=1.2$ and $\beta^{h}=0.0006$ yields: $\tau=0.0187, \quad \theta=i=0.1141$.
} 
(ii) The FR holds:

Set $\rho^{h}=\rho^{\ell}=1$ and $\beta^{h}=0.0006$. Under this circumstance, we get,

$$
\tau=0.0751, \quad \theta=i=0, \quad T^{\prime}\left(I^{h}\right)=0.0062, \quad T^{\prime}\left(I^{\ell}\right)=0.4806 .
$$

In this example, the FR is this time satisfied as a corner solution with $\tau$ being the only instrument used to affect the price of $d$. With no increase in money supply and a population growth rate of $40 \%$, the price level is falling at a rate of $28.57 \%$ per period. The policy instruments result in the following values for the arguments of the utility function and real money balances:

$$
\begin{aligned}
& c^{h}=262.656, d^{h}=102.254, L^{h}=100.214, y^{h}=341.180, x^{h}=57.566, b^{h}=-2.094, \\
& c^{\ell}=129.626, d^{\ell}=74.902, L^{\ell}=42.693, y^{\ell}=187.147, x^{\ell}=50.132, b^{\ell}=3.142 .
\end{aligned}
$$

Implementing the optimal allocation by the government in this case implies $\gamma^{\ell}=$ $0.9957, \gamma^{h \ell}=0.9488$, and $\gamma^{h}=0.7595$.

\section{Appendix C: Observability of individual consumption levels}

Let $\tau^{j}$ denote the tax rate levied on the second-period consumption of individuals of type $j$. This changes the expression for $q^{j}$ in (31) to

$$
q^{j}=\frac{1}{1+r}+\gamma^{j}\left(\frac{1}{1+g}-\frac{1}{1+r}\right)+\frac{\tau^{j}}{1+r}+\frac{\gamma^{j} \theta}{1+g} .
$$

It follows from this expression that if the fiscal authority changes $\tau^{j}$ by

$$
d \tau^{j}=-\gamma^{j} \frac{1+r}{1+g} d \theta
$$

$d q^{j}=0$ whenever the monetary authority changes $\theta$ by $d \theta$. Moreover, observe again that the change in $\theta$ induces a change in $b^{j}$ as well. As in the Proof of Proposition 1 , let the fiscal authority also change $z^{j}$ according to $d z^{j}=-d b^{j}$. This change ensures that $d y^{j}=d z^{j}+d b^{j}=0$. With $d y^{j}=d q^{j}=0$ and no change in $I^{j}$, the instituted changes leave the utility of the $h$-types and the $\ell$-types intact. 
To check resource feasibility, observe first that with $\left(q^{j}, y^{j}, I^{j}\right)$ remaining unchanged, the $j$-type's demand for $d$ does not change either. With $d d^{j}=0$, the change in the government's net tax revenue is, from the steady-state version of (20), while substituting $\tau^{j}$ for $\tau,-d b^{j}$ for $d z^{j}$, and the value of $d \tau^{j}$ from (B2)

$$
d R=\pi^{h} d b^{h}+\pi^{\ell} d b^{\ell}-\frac{1}{1+g} \sum_{j=\ell, h} \pi^{j} \gamma^{j} d^{j} d \theta
$$

As in the exercises in the text, the changes in $\theta$ and $b^{j}$ must satisfy the money injection constraint equation (27). Given that $d d^{j}=0$, we have

$$
\sum_{j=\ell, h} \pi^{j} d b^{j}=\frac{1}{1+g} \sum_{j=\ell, h} \pi^{j} \gamma^{j} d^{j} d \theta
$$

Substituting from (B4) into (B3) results in $d R=0$.

It remains for us to check the IC constraints. To that end, consider the expression that one gets for $q^{j k}$ when substitutes $\tau^{k}$ for $\tau$ in (A10). We have

$$
q^{j k}=\frac{1}{1+r}+\gamma^{j k}\left(\frac{1}{1+g}-\frac{1}{1+r}\right)+\frac{\tau^{k}}{1+r}+\frac{\gamma^{j k} \theta}{1+g} .
$$

It then follows from (B5) and (B2) that a change in $\theta$ accompanied by a change in $\tau^{k}$ that keeps $q^{k}$ constant, changes $q^{j k}$ by

$$
d q^{j k}=\frac{d \tau^{k}}{1+r}+\frac{\gamma^{j k} d \theta}{1+g}=\frac{\left(\gamma^{j k}-\gamma^{k}\right) d \theta}{1+g} .
$$

As a result, the utility of a $j k$-mimicker will change according to

$$
d v^{j k}=\frac{\partial v^{j k}}{\partial q^{j k}} d q^{j k}=-\alpha^{j k} d^{k} \frac{\left(\gamma^{j k}-\gamma^{k}\right) d \theta}{1+g} .
$$

where $\alpha^{j k}$ denotes the $j k$-mimicker's marginal utility of income. Now if $\gamma^{j k}-\gamma^{k}>0$ setting $d \theta>0$ implies that $d v^{j k}<0$ and if $\gamma^{j k}-\gamma^{k}<0$ setting $d \theta<0$ implies that $d v^{j k}<0$. Either way, the $j k$-mimicker can be made worse off allowing a Paretoimproving move. 
The upshot of this discussion is that if $\gamma^{j k}-\gamma^{k}>0$ a reform that sets $d \theta>0$ and changes $q^{j k}$ according to the above relationship will make the $j k$-mimicker worse off and allows a Pareto-improving move. On the other hand, if $\gamma^{j k}-\gamma^{k}<0$ a reform that sets $d \theta<0$ allows a Pareto-improving move. Consequently, given this information structure, fiscal policy becomes overarching and one would want to either keep inflating the economy or deflating it. Now, given the pattern of binding IC constraint, the relevant sign for us is that of $\gamma^{h \ell}-\gamma^{\ell}$ which we know is negative. Consequently, a deflationary reform of the type described always increases welfare, resulting in the optimality of the Friedman rule as a limit solution due to the constraint on the non-negativity of the nominal interest rate.

Finally, observe that the indeterminacy problem we have mentioned in the text does not arise here despite the fact that we are enabling the fiscal authority to neutralize the redistributive effects of the monetary policy. The reason for this is that, this informational structure allows fiscal authority to achieve even more. It can even determine the "virtual" price $q^{j k}$ thus being able to play with IC constraints. 


\section{References}

[1] Abel, A.: Optimal monetary growth. Journal of Monetary Economics 19, 437-450 (1987)

[2] Albanesi, S.: Redistribution and optimal monetary policy: results and open questions. Rivista di Politica Economica 97, 3-47 (2007)

[3] Atkinson, A. B., Stiglitz, J. E.: The structure of indirect taxation and economic efficiency. Journal of Public Economics 1, 97-119 (1972)

[4] Atkinson, A. B., Stiglitz, J. E.: The design of tax structure: direct versus indirect taxation. Journal of Public Economics 6, 55-75 (1976)

[5] Atkinson, A. B., and Stiglitz, J. E.: Lectures on Public Economics. McGraw-Hill, New York (1980)

[6] Boise, G., Polemarchakis, H.: Theory and practice of monetary policy. Economic Theory 27, 1-23 (2006)

[7] Chari, V. V., Christiano, L., Kehoe, P.: Optimal fiscal and monetary policy: some new results. Journal of Money, Credit and Banking 23, 519-539 (1991)

[8] Chari, V. V., Christiano, L, Kehoe, P.: Optimality of the Friedman rule in economies with distorting taxes. Journal of Monetary Economics 37, 203-233 (1996)

[9] Correia, I., Teles, P.: Is the Friedman rule optimal when money is an intermediate good? Journal of Monetary Economics 38, 223-244 (1996)

[10] Correia, I., Teles, T.: The optimal inflation tax. Review of Economic Dynamics 2, 325-346 (1999)

[11] Correia, I., Nicolini, J. P., Teles, P.: Optimal fiscal and monetary policy: equivalence results. Journal of Political Economy 116, 141-170 (2008)

[12] Crettez, B., Michel, P., Wigniolle, B.: Cash-in-advance constraints in the Diamond overlapping generations model: neutrality and optimality of monetary policies. Oxford Economic Papers 51, 431-452 (1999)

[13] Crettez, B., Michel, P., Wigniolle, B.: Optimal monetary policy, taxes, and public debt in an intertemporal equilibrium. Journal of Public Economic Theory 4, 299$316(2002)$ 
[14] Cunha, A. B.: The optimality of the Friedman rule when some distorting taxes are exogenous. Economic Theory 35, 267-291 (2008)

[15] da Costa, C. E., Werning, I.: On the optimality of the Friedman rule with heterogeneous agents and nonlinear income taxation. Journal of Political Economy 116, 82-112 (2008)

[16] De Fiore, F., Teles, P.: The optimal mix of taxes on money, consumption and income. Journal of Monetary Economics 50, 871-887 (2003)

[17] Diamond, P. A.: National debt in a neoclassical growth model. American Economic Review 55, 1126-1150 (1965)

[18] Edwards, J., Keen, M., Tuomala, M.: Income tax, commodity taxes and public good provision: A brief guide. Finanzarchiv 51, 472-487 (1994)

[19] Erceg, C. J., Henderson, D. W., Levin, A. T.: Optimal monetary policy with staggered wage and price contracts. Journal of Monetary Economics 46, 281-313 (2000)

[20] Erosa, A., and Ventura, G.: On inflation as a regressive consumption tax. Journal of Monetary Economics 49, 761-795 (2002)

[21] Friedman, M.: The optimum quantity of money. In: Friedman, M. (Ed.), The Optimum Quantity of Money and Other Essays. Aldine Publishing Company, Chicago (1969)

[22] Gahvari, F.: Lump-sum taxation and the superneutrality and optimum quantity of money in life cycle growth models. Journal of Public Economics 36, 339-367 (1988)

[23] Gahvari, F.: The Friedman rule: old and new. Journal of Monetary Economics 54, 581-589 (2007)

[24] Gahvari, F.: Friedman rule in a model with endogenous growth and cash-in-advance constraint, Journal of Money, Credit, and Banking 44, 787-823 (2012)

[25] Guidotti, P. E.,Vegh, C. A.: The optimal inflation tax when money reduces transaction costs. Journal of Monetary Economics 31, 189-205 (1993)

[26] Guiso, L., Haliassos, M., Jappelli, T.: Household Portfolios. MIT Press, Boston (2001) 
[27] Hahn, F., Solow, R.: A Critical Essay on Modern Macroeconomic Theory. Basil Blackwell, Oxford (1995)

[28] Hamada, K.: Lifetime equity and dynamic efficiency on the balanced growth path. Journal of Public Economics 1, 373-396 (1972)

[29] Ireland, P. N.: The role of countercyclical monetary policy. Journal of Political Economy 104, 704-723 (1996)

[30] Ireland, P. N.: Implementing the Friedman rule. Review of Economic Dynamics 6, 120-134 (2003)

[31] Johnson, E., Sherraden, M. S.: From financial literacy to financial capability among youth. Journal of Sociology \& Social Welfare 34, 119-145 (2007)

[32] Khan, A., King, R. G., Wolman, A. L.: Optimal monetary policy. Review of Economic Studies 70, 825-860 (2003)

[33] Kotlikoff, L. J., Bernheim, B. D.: Household financial planning and financial literacy. In: L. J. Kotlikoff (Ed.), Essays on saving, bequests, altruism, and life-cycle planning, Cambridge, MA: MIT Press, 427-478 (2001)

[34] Lai, C., Chin, C.: (In)determinacy, increasing returns, and the optimality of the Friedman rule in an endogenously growing open economy. Economic Theory 44, 69-100 (2010)

[35] Michel, P., Wigniolle, B.: Temporary bubbles. Journal of Economic Theory 112, $173-183$ (2003)

[36] Michel, P., Wigniolle, B.: Cash-in-advance constraints, bubbles, and monetary policy. Macroeconomic Dynamics 9, 28-56 (2005)

[37] Mulligan, C. B., and Sala-i-Martin, X.: The optimum quantity of money: theory and evidence. Journal of Money, Credit and Banking 29, 687-715 (1997)

[38] Mulligan, C. B., Sala-i-Martin, X.: Extensive margins and the demand for money at low interest rates. Journal of Political Economy 108, 961-991 (2000)

[39] OECD Observer: Policy Brief. http://www.oecd.org/finance/financialeducation/37087833.pdf (2006)

[40] Phelps, E. S.: The golden rule of accumulation: a fable for growthmen. American Economic Review 51, 638-643 (1961) 
[41] Phelps, E. S.: Inflation in the theory of public finance. Swedish Journal of Economics 75, 67-82 (1973)

[42] Rochon, C., and Polemarchakis, H.: Debt, liquidity and dynamics. Economic Theory $\mathbf{2 7}, 179-211(2006)$

[43] Samuelson, P. A.: An exact consumption-loan model of interest with or without the social contrivance of money. Journal of Political Economy 66, 467-482 (1958)

[44] Sandmo, A.: A note on the structure of optimal taxation. American Economic Review 64, 701-706 (1974)

[45] Schmitt-Grohé, S., Uribe, M.: Optimal fiscal and monetary policy under sticky prices. Journal of Economic Theory 114, 198-230 (2004a)

[46] Schmitt-Grohé, S., and Uribe, M.: Optimal fiscal and monetary policy under imperfect completion. Journal of Macroeconomics 26, 183-209 (2004b)

[47] Shaw, M., Chang, J., Lai, C.: (Non)optimality of the Friedman rule and optimal taxation in a growing economy with imperfect competition. Economic Letters 90, 412-420 (2006)

[48] Stiglitz, J. E.: Self-selection and Pareto efficient taxation. Journal of Public Economics 17, 213-240 (1982)

[49] Stiglitz, J. E.: In praise of Frank Ramsey's contribution to the theory of taxation. Economic Journal 125, 235-268 (2015)

[50] van der Ploeg, F., Alogoskoufis, G. S.: Money and endogenous growth. Journal of Money, Credit, and Banking 26, 771-791 (1994)

[51] Weiss, L.: The effects of money supply on economic welfare in the steady state. Econometrica 48, 565-576 (1980)

[52] Williamson, S. D.: Monetary policy and distribution. Journal of Monetary Economics 55, 1038-1053 (2008) 